\title{
Vertical differentiation via multi-tier geographical indications and the consumer perception of quality: The case of Chianti wines
}

\author{
Marco Costanigro $^{\mathrm{a}, *}$, Gabriele Scozzafava ${ }^{\mathrm{b}}$, Leonardo Casini ${ }^{\mathrm{b}}$ \\ ${ }^{a}$ Department of Agricultural and Resource Economics, Colorado State University, United States \\ ${ }^{\mathrm{b}}$ Department of Agriculture, Food, Environment and Forestry, University of Firenze, Italy
}

\section{A R T I C L E I N F O}

\section{Keywords:}

Minimum quality standards

Consumer perceptions

Geographical indications

Consumer beliefs

Consumer preferences

JEL codes:

D83

D84

L15

Q13

\begin{abstract}
A B S T R A C T
We derive and estimate a model of demand for Geographical Indications allowing for subjective and heterogeneous quality perceptions, and study vertical differentiation based on multi-tier quality labels within the context of the strategy adopted by the Chianti Consortium. Quality perceptions and wine choices are elicited in an online experiment where the number of quality tiers is augmented incrementally in a between-subject design. The empirical model includes subjective quality perceptions as an (endogenous) explanatory variable, and unexplained heterogeneity in WTP for quality as a random parameter. We find that quality perceptions are endogenous to the labeling regime, and adding a high-quality label (Chianti Classico Gran Selezione) decreases the perceived quality of all other Chianti wines, but not the competitor wines. However, the market shared lost to perception restructuring is small compared to the benefits of increased vertical differentiation.
\end{abstract}

\section{Introduction}

In 2013 the Consortium of wine producers in the Chianti Classico Geographical Indication (GI henceforth) agreed to introduce the "Gran Selezione" (Great Selection), a quality certification label, to promote an "upward expansion of the oenological offer of the Chianti territory". ${ }^{1}$

As worthwhile as this endeavour may seem, the move raised controversy among the members of the Consortium, as a Decanter article reported (Brook, 2014). After all, designations of origin tied to the Tuscan region already featured multiple tiers of quality labels, including Chianti, Chianti Classico, and Chianti Classico Riserva. Would the new label bring real value to Chianti producers or just increase bureaucratic costs? Would the Gran Selezione benefit some producers while damaging others?

Having established a large body of theoretical and empirical work on minimum quality standards and GIs, ${ }^{2}$ economists are well set to address such questions. Briefly, in markets for experience (Nelson, 1970) and credence (Darby and Karni, 1973) goods, quality labels can increase the number of consumers' choices and, at the same time, allow producers to price above marginal cost (Zago and Pick, 2004). The empirical task, therefore, is to determine the share of consumers willing to pay for the higher quality label, evaluate substitution patterns, and consider costs. $^{3}$

As it often turns out however, not all questions raised by the winemakers are so straightforward. Giovanni Poggiali's of Felsina Winery for example was concerned that "if we present our single-vineyard Rancia as Gran Selezione, then consumers will assume our other top wines such as our pure-Sangiovese Fontalloro are not as good" (Brook, 2014). Mr. Poggiali's thought points to two important concepts typically not considered in the GI literature: first, that even though quality standards linked to Protected Designation of Origin (PDO) are an objectively-defined set of practices, consumers will interpret the label subjectively. Second, and perhaps more crucially, that perceived quality is a contextual and comparative concept-production processes and sensory characteristics may remain unaltered, but the Chianti Classicos not making the cut for the Gran Selezione may lose prestige, just like the release of a "new and improved" phone cheapens the feel of the one we hold in our pocket.

The objective of this article is to establish a theoretical framework to study vertical differentiation via multi-tier GI quality certifications, test

\footnotetext{
* Corresponding author.

E-mail addresses: marco.costanigro@colostate.edu (M. Costanigro), gabriele.scozzafava@unifi.it (G. Scozzafava), leonardo.casini@unifi.it (L. Casini).

${ }^{1}$ http://www.chianticlassico.com/chianti-classico-gran-selezione/.

${ }^{2}$ See Bonroy and Constantatos (2014) for a compendium of theory results on quality labels and Deselnicu et al. (2013) for a meta-analysis of GI valuation studies.

${ }^{3}$ Ex ante, this can be accomplished via choice (e.g. (Mueller et al., 2010; Costanigro et al., 2014a), or lab experiments (e.g. Gustafson et al., 2016). Ex post, scanner data can be used, as in Torrisi et al. (2006).
} 
whether restructuring of perceptions effects of the type suggested by Mr. Poggiali can be detected and quantified, and understand the pros and cons of the strategy adopted by the Chianti Classico consortium. As the question is fundamentally empirical, our approach relies on an online experiment where consumers' quality perceptions and product choices are elicited under different labeling scenarios. The type of heuristics we have in mind are similar to those considered in the product line and umbrella branding literature, where upward or downward brand extensions affect consumers' perceptions of all the products marketed by the same brand (Chintagunta, 1996; Heath et al., 2011). The introduction of higher quality products is generally thought to increase brand equity (Randall et al., 1998) and possibly market power (Kadiyali et al., 1998), but it is also possible for the strategy to backfire and damage the differentiating brand (Caldieraro et al., 2015).

Chianti producers have been pursuing a strategy of quality standards and product differentiation for centuries ${ }^{4}$; and this is no hyperbole. The Lega del Chianti was founded in Florence in the thirteenth century to regulate administrative relations with the leading producers of a red wine made with Sangiovese grapes from the Chianti region, and the first notarial document in which the name Chianti is used to refer to wines produced in that region dates to 1398. In 1716 the Grand Duke Cosimo III de' Medici issued a decree in Florence specifying the boundaries of the areas in which Chianti wines could be produced, and set up a Congregation to oversee the production, shipping, fraud-control and marketing of wine.

As the popularity of Chianti wines increased through the centuries, the acreage and region of production expanded beyond the traditional boundaries, but in 1932 the modern Consortium protecting the authenticity of Chianti wines established the Chianti Classico label and its distinctive red rooster trademark to identify the wines produced within the historical (1716) region, differentiating them from the more generic wines produced in the broader Chianti. In 1984, Chianti obtained the DOCG designation (Denominazione di Origine Controllata e Garantita Denomination of Controlled and Guaranteed Origin), which is awarded to wines of certified origin with codified production processes and guaranteed wine quality; while in 1996 the Chianti Classico became a DOCG independent of the broader Chianti DOCG.

Table 1 portrays the main production differences between the two denominations. Chianti Classico wines with higher alcohol content ( $>12.5 \%$ ) with at least two years of aging may be further qualified as Reserve (Chianti Classico Riserva). The "Gran Selezione" label (Great Selection) identifies a limited number of wines meeting very stringent quality standards (including approval by a tasting commission). It is important to note that this type of multi-tier labelling strategy is not unique to Chianti. Rosso di Montalcino and Brunello di Montalcino for example are wines produced exclusively in the territory of the Municipality of Montalcino, but quality standards are much more stringent for Brunello than for Rosso, so that the two wines are sold at very different price points (see Table 1 ).

The theory of vertical differentiation via GI (Zago and Pick, 2004; Moschini et al., 2008; Menapace and Moschini, 2011; Mérel and Sexton, 2012) generally assumes that certification of production processes communicates a certain quality level (e.g. high vs. low), and the interpretation of a signal is not affected by the presence/absence of other labels. This is reasonable when each region certifies a single label, segmenting the market into unlabeled vs. GI product, but less so for the case of the multi-tier strategy adopted in the Chianti and other viticultural areas (e.g. Montalcino, Bordeaux). A contribution of this article is therefore to examine how multi-tier quality labels affect the distribution of the quality marketed under a given GI, and then model how consumers' perceptions may change in response.

The context and modeling assumptions are tied to the regulations

\footnotetext{
${ }^{4}$ See Meloni and Swinnen (2018) for a detailed historical account of wine GIs in Europe.
}

surrounding the European Protected Designations of Origin, where a causal link between labeled production practices and product quality is established (EU 1151/2012). ${ }^{5}$ In addition to informing consumers and supporting a diversified food production, the stated objectives of European regulations include guaranteeing the profitability for producers of traditional agricultural products as a rural development strategy (Gragnani, 2013). The analysis of consumer perceptions and choices we developed here allows us to offer some considerations on the conditions under which multi-tier GI certifications can promote such objectives, but also raise some caveats related to distributional effects.

The first hypothesis we raise regarding consumer perceptions follows the standard assumption that consumers are both rational and well informed about the certification standards, so that perceptions match the expected quality marketed under each label (e.g. Zago and Pick, 2004). The second and third hypotheses waive rational expectations to integrate Steenkamp' (1990) model of quality perceptions, positing that the interpretation of food labels results from a subject-object interaction, and is "neither completely subjective nor wholly objective (p.312)". In this context food labels and production practices are essentially quality cues which consumers use to infer important quality traits (Messer et al., 2017) according to an individual's knowledge and beliefs.

Even though wine consumption can certainly inform quality perceptions, the signaling role of labels remains central for two main reasons. First, in a market with a vast number of differentiated products (such as wine), the number of consumers having direct experience is generally small compared to first-time, uninformed buyers. Second, and perhaps more importantly, ample evidence shows that labels and other signals can influence (or bias) quality perceptions, even after consumption. For example, information about the high price of a wine not only makes people express higher quality ratings after tasting (as in Almenberg and Dreber, 2011), but has been shown to influence the very neural processes activated by pleasant experiences (Plassmann et al., 2008). Similarly, identical cookies seem to taste better when labeled as organic (Lee et al., 2013).

As Verdú et al. point out (2004), “[consumers] are not experts and probably do not know anything about the processes involved in the production and ageing of wines". Teuber (2011) finds that, even among the very consumers of a GI product (Hessian apple cider) "consumers' awareness and knowledge about GI is very limited". One can therefore hypothesize that a Gran Selezione may be interpreted as a signal of higher quality, but consumers unfamiliar with GI regulations may naively interpret the label as a newly developed high-quality product (rather than, at least in part, a reclassification of existing wines). Following this logic, a testable hypothesis is that perceptions of other Chianti wines may be independent of the presence/absence of the Gran Selezione. Lastly, if we accept that quality perceptions are inherently subjective, then systematic and heuristic biases (see for example Kahneman et al., 1991) may play an important role. The "comparative stigma" idea raised by Mr. Poggiali follows this logic, suggesting that the presence of a Gran Selezione may cheapen the perceived quality of all other wines marketed under the Chianti umbrella, and is the third hypothesis we test.

Having relaxed the assumption that consumers' perceptions necessarily match the expected quality output under each labeling standard, we derive a model of demand for experience goods based on the

\footnotetext{
${ }^{5}$ Geographical Indications in the European Union include Protected Designation of Origin (PDO) and Protected Geographical Indications (PGI). For PGIs, producers need to be able to establish a clear link between quality characteristics and an agricultural region. PDOs additionally require that the whole production process takes place in the defined geographical area. The DOCG (Denominazione di Origine Controllata e Garantita) label used for Chianti is a PDO scheme. See https://ec.europa.eu/agriculture/quality/ schemes_en.
} 
Table 1

Minimum quality standards and median prices for Chianti and Montalcino wines. ${ }^{\mathrm{a}}$

\begin{tabular}{|c|c|c|c|c|c|c|}
\hline & $\begin{array}{l}\text { Chianti } \\
\text { D.O.C.G. }\end{array}$ & $\begin{array}{l}\text { Chianti Classico } \\
\text { D.O.C.G. }\end{array}$ & $\begin{array}{l}\text { Chianti Classico } \\
\text { D.O.C.G. Riserva }\end{array}$ & $\begin{array}{l}\text { Chianti Classico D.O.C.G. } \\
\text { Gran Selezione }\end{array}$ & $\begin{array}{l}\text { Rosso di Montalcino } \\
\text { D.O.C. }\end{array}$ & $\begin{array}{l}\text { Brunello di Montalcino } \\
\text { D.O.C.G }\end{array}$ \\
\hline Area (Hectares) & 71,800 & 7000 & 7000 & 700 & 3600 & 3600 \\
\hline $\begin{array}{l}\text { Maximum Production (Ton/ } \\
\text { Hectare) }\end{array}$ & 9 & 7.5 & 7.5 & 7.5 & 9 & 8 \\
\hline Min \% Sangiovese & 70 & 80 & 80 & 80 & 100 & 100 \\
\hline Min \% Alcohol & 12 & 12 & 12.5 & 13 & 12 & 12.5 \\
\hline Min Aging (Months) & 3 & 10 & 24 & 30 & 12 & 60 \\
\hline Mandatory Bottling on Premises & No & No & No & Yes & No & No \\
\hline $\begin{array}{l}\text { Approval by Tasting } \\
\text { Commission }\end{array}$ & No & No & No & Yes & No & Yes \\
\hline $\begin{array}{l}\text { Median Market Price (IRI, } \\
\text { 2015) }\end{array}$ & $€ 6$ & $€ 13$ & $€ 20$ & $€ 25$ & $€ 9$ & $€ 30$ \\
\hline
\end{tabular}

a Source: authors elaboration from www.consorziovinochianti.it, www.chianticlassico.com.

Mussa and Rosen (1978) framework, expanding the GI literature to consider the case of multi-tier certifications with quality perceptions endogenous to the labeling regime. The model is used to show how changes in market shares following the introduction of a new label can be parsed into two separate effects: choice availability, linked to the fraction of consumers who prefer higher quality, and perception restructuring, whose effects cannot be signed $a$ priori. Then, we use data from a choice experiment to estimate the model, predict market shares, and quantify each effect.

The importance of distinguishing preferences from beliefs/perceptions to understand food choices has also been raised by recent experimental work on food labels (Lusk et al., 2013; Costanigro et al., 2015), even though not in the context of GIs. This distinction may seem purely academic to some: whatever the cause, an ex-ante investigation (e.g. via lab or choice experiment) of the share of consumers who will buy the Gran Selezione, and the implied substitution patterns (i.e. cannibalization of other Chianti wines vs. market gains against competitors), would provide all the information wine makers need to support it or oppose it. This view, however, misses some important implications.

The overarching issue is the identification problem raised by Manski (2004): if observed choices are consistent with multiple combinations of subjective beliefs (in this case, about product quality) and preferences (i.e. WTP for quality), then identifying preferences from choice data requires knowing or observing consumers' beliefs. Were the new label unsuccessful, the consortium would want to know if consumers are just happy with the quality of a lower tier Chianti Classico (suggestive of market saturation), or because they don't think that a Gran Selezione will differ that much from a Classico (implying a need for further differentiation or consumer messaging), and this cannot be ascertained by simply observing or estimating market shares.

To measure how multi-tier labels influence quality perceptions we designed four between-subject scenarios with an increasing number of competing quality standards, and then asked participants to rate product quality of each GI label via Likert scales. The use of psychometric or other subjective (Likert-type) constructs to explain WTP for labels has been proposed before (Costanigro et al., 2014a, 2014b; Malone and Lusk, 2017b) and has some clearly appealing features. For one, Likert scales are easily understood by survey participants, even in an online setting, and it is no coincidence that wine magazines (Wine Spectator, Wine Enthusiast, Decanter etc.) and consumer review websites (e.g. Vivino.com) use a similar system to report quality ratings (i.e. 1-100 scores or 1-5 stars). The representation of quality differences on a linear spectrum is also consistent with the vast body of theory on asymmetric information, from Akerlof (1970) and Mussa and Rosen (1978), to the work on minimum quality standards (Leland, 1979; Shapiro, 1983; Bockstael, 1984; Boom, 1995) and GI labeling (Winfree and McCluskey, 2005; Moschini et al., 2008; Menapace and Moschini, 2011).
One significant drawback of Likert scales, however, is that they are notoriously susceptible to framing effects. Here, we borrow a remedy from the multiple price list experimental literature (see Andersen et al., 2006) by randomly assigning participants to two different types of elicitation scales, controlling econometrically for framing effects. The use of stated (rather than revealed) preference methods also comes with the standard caveats (see for example Brooks and Lusk, 2010), but choice experiments are particularly well suited to investigate the research questions examined here. Just like vertical differentiation models abstract from quantity (assuming that consumers purchase only one product) to study price-quality relationships, choice experiments require participants to select one preferred product within a choice set, isolating the tradeoffs central to a model of vertical differentiation. Indeed, the close analogy between the theoretical and empirical model is a prominent strength of the approach we propose. With measurements of quality perceptions in hand, one can estimate a choice model where product quality appears as a right-hand-side variable, as it is customary in virtually all vertical differentiation models.

While the advantages of controlling for quality perceptions are substantive, it is also true that the use of subjective constructs as regressors begs the question of endogeneity, and the design of a careful instrumentation strategy. After all, perceptions are by definition idiosyncratic, and therefore potentially correlated with the residual. Acknowledging this problem, we implement a two-pronged instrumentation strategy. First, a series of subject-specific, randomized information treatments designed to induce exogenous variation in quality perceptions, a methodology similar to the one adopted by Teisl and Roe (2010) to control for endogenous beliefs while estimating WTP to avoid foodborne pathogens. Second, we use perceptions relative to one label as instruments for another, following the strategy proposed by Gergaud et al. (2017, for endogenous collective reputations) and Malone and Lusk (2017a, for beer quality perceptions). A model of choice with subjective perceptions and heterogeneous (random) preferences for quality is then estimated adopting a control function approach (Petrin and Train, 2010) to correct for endogeneity. Estimated parameters are then used to predict market shares before and after the introduction of the new quality tier, while separating the effects of perception restructuring from choice availability effects induced by the introduction of the Gran Selezione. We conclude by examining the policy implications of the multi-tier differentiation strategy from the perspective of a GI vs. the individual firm.

\section{Conceptual model and theoretical framework}

In this section we develop a formal model of how multi-tier labels tied to the adoption of increasingly stringent quality standards may affect product quality, consumer perceptions and purchasing choices. The general framework draws from Moschini et al. (2008), with some major modifications. On the supply side, we consider the more realistic 
case where some producers surpass the minimum quality standards imposed by the GI regulation, so that a label is tied to a distribution of quality, rather than a precise level. On the demand side, we model GI labels as cues influencing a consumer's subjective perception of quality, rather than an objective measurement uniformly interpreted by all consumers. The model developed here is quite general, but we present it within the context of the Chianti consortium differentiation strategy, where four labels were progressively introduced: Chianti (C), Chianti Classico (CC), Chianti Classico Riserva (CCR) and Chianti Classico Gran Selezione (CCGS).

Assume first that, in the absence of GI labeling, quality is uniformly distributed according to $q \sim U\left[q_{\min }, q_{\max }\right]$, where $q_{\min }$ represents the minimum quality imposed on all products (e.g. to meet food safety standards and adulteration laws), and $q_{\max }$ is the maximum quality achievable with the known technology. Therefore, the mean quality of an unlabeled wine is $\mu=1 / 2\left(q_{\max }-q_{\min }\right)$. One may wonder why a firm would ever produce at a quality level above $q_{\min }$ in an experience good market where information about quality is asymmetric. The rationale is that market equilibria where products surpassing minimum quality standards are offered can be supported by firm reputation dynamics (see Shapiro, 1983; Menapace and Moschini, 2011). While we do not directly model and abstract from firm reputations, they are undoubtedly present in the wine (see Costanigro et al., 2010) and many other food industries, countering the free-ride incentive induced by the collective GI labeling (Winfree and McCluskey, 2005, Costanigro et al., 2012).

Consider now the effect of the gradual introduction of four increasingly stringent minimum quality standards, and assume that the production processes codified by the differentiating labels (Table 1) alter the quality of the product in some objective way, so that $q_{\min }<q_{\min }^{C}<q_{\min }^{C C}<q_{\min }^{C C R}<q_{\min }^{C C G S}<q_{\max }$ holds. That is, the model considers the case of a GI imposing meaningful standards, and not just leveraging generic ethnocentric consumer preferences (as in Desquilbet and Monier-Dilhan, 2015). We also assume that all producers in the GI who surpass a certain standard $q_{\min }^{l}, l=\mathrm{C}, \mathrm{CC}, \mathrm{CCR}, \mathrm{CCGS}$, will automatically qualify for the use of the label.

Let now $k$ represent the number of quality standards under a given GI label. When the first label is introduced $(k=1)$, the quality distribution of a wine (in this case, Chianti DOCG) is $q_{k=1}^{C} \sim U\left[q_{\min }^{C}, q_{\max }\right]$, with mean quality $\mu_{k=1}^{C}=1 / 2\left(q_{\max }-q_{\min }^{C}\right)$, greater than the average quality of an unlabeled wine $\mu$. Then, Chianti Classico wines are introduced, with $q_{k=2}^{C C} \sim U\left[q_{\min }^{C C}, q_{\max }\right]$ and $\mu_{k=2}^{C C}=1 / 2\left(q_{\max }-q_{\min }^{C C}\right)$. The important point here is that all Chianti wines meeting the minimum quality standard $q_{\mathrm{min}}^{C C}$ are relabeled as CC, so that the quality distribution of $C$ wines changes to $q_{k=2}^{C} \sim U\left[q_{\min }^{C}, q_{\min }^{C C}\right]$, with $\mu_{k=2}^{C}=1 / 2\left(q_{\min }^{C C}-q_{\min }^{C}\right)$ and $\mu_{k=2}^{C}<\mu_{k=1}^{C}<\mu_{k=2}^{C C}$. The Chianti Classico Riserva is introduced in stage three, with $q_{k=3}^{C C R} \sim U\left[q_{\min }^{C C R}, q_{\max }\right]$ and $\mu_{k=3}^{C C R}=1 / 2\left(q_{\max }-q_{\min }^{C C R}\right)$. Again, a percentage of the CC wines are reclassified as CCR, so that $q_{k=3}^{C C} \sim U\left[q_{\min }^{C C}, q_{\min }^{C C R}\right]$ and $\mu_{k=3}^{C C}=1 / 2\left(q_{\min }^{C C R}-q_{\min }^{C C}\right)$. However, the quality of $\mathrm{C}$ wines remains unaltered, i.e. $\mu_{k=3}^{C}=\mu_{k=2}^{C}$, as no $\mathrm{C}$ wines are reclassified at $k=3$. This leapfrog game, where the newly introduced "top quality" label steals the upper end of the quality spectrum from the runner-up continues in stage four, when CCGS is introduced.

The central question we raise relates to how the introduction of new, more stringent GI standards changes perceptions for the labels previously released, and whether or not such changes conform to the conclusions we can draw from this "objective" model of quality. Letting $\widetilde{q}_{i k}^{l}$ represent the quality perception associated by consumer $i$ to label $l$ under a regime of $k$ labels, one first hypothesis is that any mistake in judgement is Gaussian white noise and, on average, consumers are both rational and well informed. In such case, the mean (across the consumer population) quality perception $E\left[\widetilde{q}_{i k}^{l}\right]$ will conform to the rankings implied by the previous model of quality. Focusing on the introduction of the Gran Selezione, the rational \& informed hypothesis implies the following evolution in perceptions as $k$ goes from three to four:
Chianti: $E\left(\widetilde{q}_{k=3}^{C}\right)=E\left(\widetilde{q}_{k=4}^{C}\right)$

Chianti Classico: $E\left(\widetilde{q}_{k=3}^{C C}\right)=E\left(\widetilde{q}_{k=4}^{C C}\right)$

Chianti Classico Riserva: $E\left(\widetilde{q}_{k=3}^{C C R}\right)>E\left(\widetilde{q}_{k=4}^{C C R}\right)$.

Alternatively, naive and uninformed consumers may assume that new GI labels certify newly introduced products, taking the new quality standards as independent from other existing labels. This would imply that mean perceptions remain unchanged across stages, as in:

Chianti: $E\left(\widetilde{q}_{k=3}^{C}\right)=E\left(\widetilde{q}_{k=4}^{C}\right)$

Chianti Classico: $E\left(\widetilde{q}_{k=3}^{C C}\right)=E\left(\widetilde{q}_{k=4}^{C C}\right)$

Chianti Classico Riserva: $E\left(\widetilde{q}_{k=3}^{C C R}\right)=E\left(\widetilde{q}_{k=4}^{C C R}\right)$.

Lastly, the comparative stigma hypothesis suggests that perceptions are endogenous to the labeling regime, and more specifically that introducing higher quality labels (i.e. with more stringent standards) will damage the perceived quality of all lower tier products. In terms of quality perceptions, the implied relationship are:

Chianti: $E\left(\widetilde{q}_{k=3}^{C}\right)>E\left(\widetilde{q}_{k=4}^{C}\right)$

Chianti Classico: $E\left(\widetilde{q}_{k=3}^{C C}\right)>E\left(\widetilde{q}_{k=4}^{C C}\right)$

Chianti Classico Riserva: $E\left(\widetilde{q}_{k=3}^{C C R}\right)>E\left(\widetilde{q}_{k=4}^{C C R}\right)$.

We now turn our attention to modeling how restructuring of quality perceptions may affect demand for experience goods after the introduction of a new label. The task is to separate changes in market shares owed to the availability of a new, higher quality choice from the effects attributable to restructuring of perceptions. This is simpler to accomplish by ignoring, for now, cross-consumer heterogeneity in perceptions. So, let $\widetilde{q}_{k}^{l}$ represent the quality consumers associate to label $l$ under a regime of $k$ competing quality standards labels. Adopting the Mussa and Rosen (1978) framework, consumers' utility depends on product quality, price, and a parameter $\left(\theta_{i}\right)$ capturing the propensity for buying high quality, i.e. $U\left(q, p, \theta_{i}\right)$.

The utility of alternative choices when only one label, C, is available can be represented as:

$U_{i}=\left\{\begin{array}{lc}\theta_{i} \widetilde{q}_{k=1}^{C}-p^{C} & \text { if a Chianti is bought } \\ 0 & \text { otherwhise }\end{array}\right.$.

Letting $\stackrel{0 \rightarrow C}{\theta_{k=1}}=\frac{p^{C}}{\widetilde{q}_{k=1}^{C}}$ represent the marginal WTP for quality of a consumer who is indifferent between buying nothing and making a purchase, imposing strictly positive quality perceptions/prices and under the typical (Akerlof, 1970; Mussa and Rosen, 1978; Shapiro, 1983; Moschini et al., 2008) simplifying assumption that $\theta \sim$ Uniform $[0,1]$; one can represent the demand for Chianti in a market of $\mathrm{N}$ consumers as $x_{k=1}^{C}=N\left[1-\stackrel{0 \rightarrow C}{\theta_{k=1}}\right]$, while $N\left[\stackrel{0 \rightarrow C}{\theta_{k=1}}\right]$ consumers will buy nothing (i.e., the market is uncovered).

Now consider the introduction of the Chianti Classico (CC), and assume that perceptions and prices under this two-labels regime conforms with the inequalities $\widetilde{q}_{k=2}^{C C}>\widetilde{q}_{k=2}^{C}$ and $p^{C C}>p^{C}$; but it is possible that $\widetilde{q}_{k=2}^{C} \neq \widetilde{q}_{k=1}^{C}$. That is, the presence of CC wines may change how consumers view $\mathrm{C}$ wines. The implied choice becomes:

$U_{i}=\left\{\begin{array}{lc}\theta_{i} \widetilde{q}_{k=2}^{C C}-p^{C C} & \text { If CC is bought } \\ \theta_{i} \widetilde{q}_{k=2}^{C}-p^{C} & \text { if } C \text { is bought } \\ 0 & \text { otherwise }\end{array}\right.$

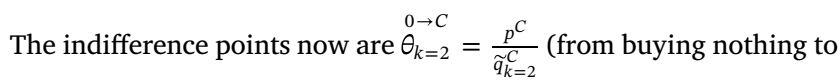

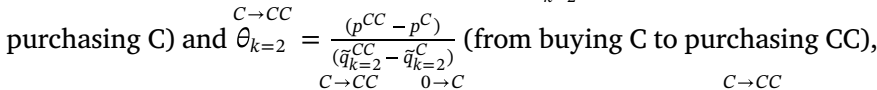
with demands $x_{k=2}^{C}=N\left[\begin{array}{c}C \rightarrow C C \\ \theta_{k=2}-\theta_{k=2} \rightarrow C\end{array}\right]$ and $x_{k=2}^{C C}=N\left[1-{ }_{k=2}^{C \rightarrow C C}\right.$; while

$N\left[\stackrel{0 \rightarrow C}{\theta_{k=2}}\right]$ will buy nothing. So, the change in demand for $C$ following the introduction of CC can be expressed as: 
$x_{k=1}^{C}-x_{k=2}^{C}=N\left[\left(\begin{array}{ccc}0 \rightarrow C & 0 \rightarrow C & C \rightarrow C C \\ \theta_{k=2} & \left.-\stackrel{\theta}{\theta=1}_{k=1}\right) & -{ }_{k=2}\end{array}\right]\right.$.

Eq. (6) details how the reduction in demand for C after CC wines become available can be attributed to two distinct factors: one owed to perceptions restructuring (embedded in the term $\left[\theta_{k=2}-\theta_{k=1}\right]$ ), and one owed to "choice availability" (captured by $\theta_{k=2}$ ), where some consumers prefer to buy higher quality when made available. This decomposition could be also derived for the case of three and four labels $(k=3,4)$ and, depending on how consumers adjust perceptions after the introduction of a new label, the perception restructuring effect will be zero (naïve consumers), affect only the $k^{\text {th }}-1$ label (rational and informed), or all labels marketed under a given GI (comparative stigma).

We now introduce heterogeneous quality perceptions and frame the fundamental structure for the empirical model of choice we are set to estimate. Assume that a consumer faces a choice between $l=1, \ldots, L$ different labels, and $\widetilde{q}_{i l}$ represents how consumer $i$ perceives label $l$, so that

$U_{i}=\left\{\begin{array}{lc}\theta_{i} \widetilde{q}_{i l}-p_{l} & \text { if product } l \text { is bought } \\ 0 & \text { otherwhise }\end{array}\right.$

When an empirical measure of $\widetilde{q}_{i l}$ is available, as in our case, the corresponding empirical parameterization would be:

$U_{i l}=\alpha_{l}+\beta p_{i l}+\theta_{i} \widetilde{q}_{i l}+\varepsilon_{i l} \quad$ for $l=1, \ldots, L ;$

where $\alpha_{l}$ is a label-specific intercept, $\beta *(-1)$ is the marginal utility of money and $\theta_{i}$ is the marginal utility of quality.

Unexplained heterogeneity in the valuation of quality, represented as a random variable with given density function in theory models, can be mirrored in the empirical setting by specifying a single parameter (i.e. $\theta_{i}$ the valuation of quality) as a random coefficient (McFadden and Train, 2000). By directly controlling for quality perceptions, we avoid confounding heterogeneity in WTP for quality and variation in quality perceptions, which leads to ambiguous results and potentially misconstrued interpretations (Lusk et al., 2013). Estimation can be accomplished by assuming a specific density $f(\theta)$, and then estimating $E\left[\theta_{i}\right]$ and $\operatorname{Var}\left[\theta_{i}\right]$ via maximum simulated likelihood (McFadden and Train, 2000).

Letting the error term $\varepsilon_{i l}$ be distributed iid extreme value (independent over labels), the probability that consumer $i$ will prefer label $l$ takes the mixed logit form

$P_{i l}=\int \frac{\exp \left(\alpha_{l}+\beta p_{i l}+\theta_{i} \widetilde{q}_{i l}\right)}{\sum_{l} \exp \left(\alpha_{l}+\beta p_{i l}+\theta_{i} \widetilde{q}_{i l}\right)} f(\theta) d \theta$.

One substantive problem with the model in Eqs. (8) and (9) is that consistent estimation of discrete choice models requires exogenous (independent of $\varepsilon_{i l}$ ) explanatory variables, implying that the use of the subjective quality perceptions $\widetilde{q}_{i l}$ as right-hand-side variables may produce biased estimates. To amend the problem, we adopt the control function approach proposed by Petrin and Train (2010), where residuals obtained by regressing the potentially endogenous variable on a set of instruments are included as an additional regressor in the choice model. The procedure requires expressing the endogenous variable as a function of observed instruments $z_{i l}$ and unobserved factors $\mu_{i l}$ correlated with $\varepsilon_{i l}$, as in

$\widetilde{q}_{i l}=W\left(\mathbf{z}_{i l}, \gamma\right)+\mu_{i l}$

where $z_{i l}$ is independent of $\varepsilon_{i l}$ and $\mu_{i l}$. If Eq. (10) can be estimated, then the residuals $\hat{\mu}_{i l}$ can be included (8), thereby controlling for endogeneity.

\section{Experimental design and survey description}

To estimate the model in Eq. (8), we conducted an online choice experiment where both quality perceptions and product choices were elicited. The experimental design was first obtained for a scenario including a full palette of differentiated Chianti wines (C, CC, CCR CCGS), a competitor wine (either Rosso di Montalcino DOC or Brunello di Montalcino DOCG, at random), and a "none of the above" option. The Montalcino wines are ideal competitors, as they also are Sangiovese-based Tuscan wines with multi-tier quality labels.

Consistently with the focus of the vertical differentiation models in (8), only two attributes were included: the wine (as defined by the GI label) and its price. As the price range of a Brunello and an entry-level Chianti will never overlap in the real world, we opted for a labeled choice experiment with price levels specific to each GI label (see BekkerGrob et al., 2010 for a discussion of labeled vs. unlabeled or generic experiments). Median market prices were obtained using scanner data ( 6 , $€ 13, € 20$, and $€ 25$ for C, CC, CCR, and CCGR, $€ 9$ and $€ 30$ for Rosso and Brunello; IRI Infoscan, 2015), and price levels in the experiment varied above and below each median (4 levels: median $\pm 20 \%$ and median $\pm 30 \%$ ). Based on these attributes and levels, a fractional factorial orthogonal design of 12 choice sets was obtained using Ngene $\complement$.

Four between-subject, randomized experimental treatments were implemented with the purpose of simulating choices under the four scenarios $(k=1, \ldots, 4)$ of increasing vertical differentiation. In scenario I (150 participants) only the base (C) Chianti wine was available, scenario II (250 participants) included both C and CC, scenario III (300 participants) had C, CC and CCR, and scenario IV (500 participants) presented the full palette of four Chianti wines. In all treatments, each choice set included one or more Chianti options, a competitor wine (Rosso or Brunello), and the opt-out "none of these wines" alternative.

Wine marketing research has shown that consumers may value different attributes/qualities depending on the occasion of consumption (Quester and Smart, 1998) and price segment (Costanigro et al., 2007). Given the extent of differentiation between the wines included in our experiment, it is quite plausible that a wine preferred for an everyday consumption situation would not be selected for a special occasion, and vice versa. To provide additional context to the choice scenario, two purchasing questions were posed in each choice set: (1) which wine would one purchase for everyday consumption ("consumo quotidiano") and (2) which wine would one purchase for a special occasion ("occasione speciale"). A choice set extracted from the design for scenario IV is presented in Fig. 1.

\subsection{Survey flow}

The online survey was administered to a panel of Italian red wine consumers by a specialized marketing firm in August 2015. The sample was stratified to match, within the limits of an online survey, the statistics on gender, age and region of residence of the Italian population.

Randomized information treatment: after the initial screening questions, participants were exposed to a randomized information treatment. The rationale of this treatment was introducing exogenous variation in perceived quality, thereby creating a set of instrumental variables to estimate Eq. (10). The full information set comprised a total of eight screenshots, presenting formal descriptions and definitions of the wine labels to appear in the choice experiment. This included a definition of a Protected Designation of Origin (Denominazione di Origine Controllata e Garantita, or DOCG), the meaning and use of the term "riserva" (reserve) in Chianti wines, and one statement describing the region of production, allowed grape varieties and the production/selection process of each wine label appearing in the choice experiment. Finally, the schematic summary of the production protocols adopted for each label in Table 1 was also used as an information treatment. The total number of treatments assigned to each participant, the specific information bullets presented and their ordering were all randomized, while the information set to draw from was kept consistent with the extant labeling regime (Scenario I-Scenario IV). ${ }^{6}$ To stimulate participants' attention to the information treatments, each screenshot was displayed for a

\footnotetext{
${ }^{6}$ For example, for participants in scenario III Table 1 would not include the information about CCGS.
} 


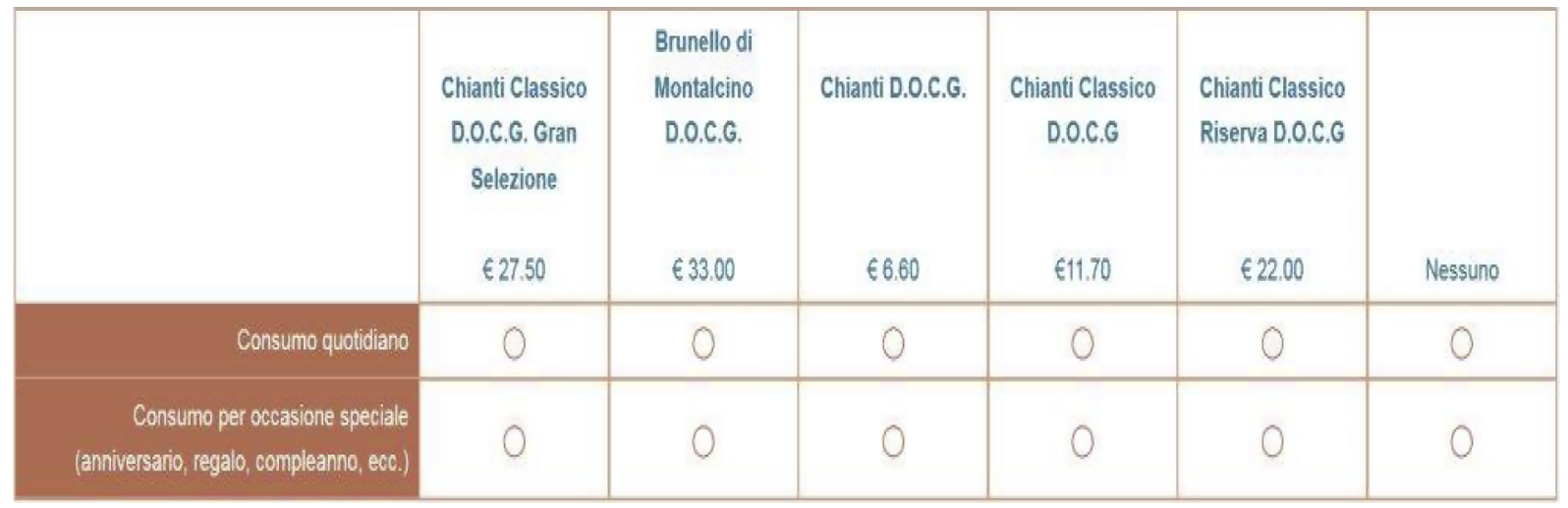

Fig. 1. A screenshot showing a choice set including four Chianti labels (Scenario IV) and Brunello as competitor wine.

minimum of $20 \mathrm{~s}$, as in McFadden and Lusk (2015).

Elicitation of quality expectations: after the information treatment, participants were asked to rate the quality of the wines in the labeling scenario, so that an empirical measure of $\widetilde{q}_{i l}$ in Eq. (8) would be available. Participants located each product on a scale ranging from lower to higher quality (minore qualità, maggiore qualità, see Fig. 2), with no other numerical markings, and numerical values in partitioning the quality spectrum were assigned only later for econometrical purposes. To account and control for possible framing effects, perceptions were elicited using one of two survey tools (at random). In one case, participants used label-specific sliding bars going from lower to higher quality (see Fig. 2, upper panel). In the second case, participants were instructed to communicate perceptions by dragging and dropping each wine label on a single line representing the quality spectrum, from lower to higher (see Fig. 2, lower). Participants who used this rating tool were also informed that, if two wines were similar in quality, the labels could be overlapped. With both tools, the order in which the wines were presented on the screen was randomized to avoid suggesting an implicit ordering in the quality of the wines.

Choice experiment and closing questions: after eliciting quality perceptions, each subject answered the 12 choice sets of the previously described experiment. The last section of the survey asked a series of questions related to an individual's typical wine consumption, his or her familiarity with the wines presented in the experiment, a self-assessment of wine expertise (1-10, low to high), family income and food expenditure.

\section{Empirical estimation and results}

Table 2 presents the average quality perceptions (elicited with the tools presented in Fig. 2 and projected to a $0-100$ numerical scale) across labeling regime. A first result is that there is little doubt that quality perceptions for Chianti wines change across scenario. A nonparametric k-sample test for equality of medians ${ }^{7}$ strongly rejects the null hypothesis for all Chianti wines, while the same hypothesis is rejected at $\alpha=0.05$ for the Rosso wines (but not at $\alpha=0.01$ ), and not rejected at any conventional level of significance for Brunello.

Some patterns can also be easily devised. For the entry level Chianti (C), elicited perceptions decline from an average of 71 (scenario I) to 64 (sc. II), 59 (sc. III) and finally 53 (sc. IV). The same, unequivocal declining pattern across treatments can be also discerned for CC and CCR. The variation in the perception of Rosso and Brunello, on the other hand, appears erratic for the case of Rosso, and minor for Brunello. Nonparametric fits comparing quality perceptions for Chianti $\mathrm{C}$ and Brunello across scenario I and IV (Fig. 3) display a notable change in the

\footnotetext{
${ }^{7}$ Results for parametric tests of equality of means are analogous, but they rely on the stronger and assumption of multivariate normality, so we do not report them.
}

distribution of perceptions for $\mathrm{C}$ wines, but not Brunello.

A formal test of hypotheses (1)-(3) can be carried out in a simple form by using the data from Scenarios III and IV, and regressing the perceived quality of a wine on a dummy variable indicating Scenario IV (plus a constant term), so that changes in perceptions between scenarios are measured by the dummy coefficient. To ascertain the robustness of our results, the regression is estimated separately for the data from the likert vs. the drag-and-drop elicitation tools. Results are also included in Table 2. As one can note, the coefficient for the Scenario IV dummy variable is negative and significant for all Chianti wines (the one exception is CCR with likert data, which is still negative but nonsignificant), implying that the perceived quality of C, CC, and CCR is lower when a GS option is available. This results is inconsistent with both the rational \& informed, and the naïve \& uniformed hypotheses, while the comparative stigma hypothesis is not rejected. As a falsification test, the same regression was estimated for Rosso and Brunello, and we find that the corresponding estimates are non-significant.

To build the control function, the model of quality perceptions in Eq. (10) was first estimated via seemingly unrelated regressions (i.e. SUR, Zellner, 1962) where the perceived quality of each wine was regressed on the randomized information treatments (see Teisl and Roe, 2010), quality elicitation tools, and cross-label perceptions (Gergaud et al., 2017; Malone and Lusk, 2017a). That is $\widetilde{q}_{i \neq l}$, the perceptions associated with labels other than $l$, are used to predict $\widetilde{q}_{i=l}$. Results for the preferred model specification in scenarios III (lower panel) and IV (upper panel) are summarized in Table $3 .^{8}$ Each column presents the results for each wine included in the system of equations (C, CC, CCR, CCGS, Brunello, Rosso), while the horizontal rows reports regressors and estimated coefficients. In general, the randomized information treatments were only mildly effective at changing quality perceptions. The description of the cultural practices of a given label (InfoLabel) is never significant, while increasing the number of informational facts presented (InfoNum) have some cumulative effect for the higher quality labels. Presenting Table 1 (CompTable) was the most effective information treatment, perhaps because of its inherent comparative layout. Participants who were randomly assigned to the drag-and-drop (Frame1 $=1$ ) elicitation tool tended to assign lower quality scores than those who used the likert scale (Frame1 $=0$ ). Cross-label perceptions, on the other end, tend to correlate rather strongly.

Table 4 presents the choice and market value shares for everyday consumption vs. special occasion, broken down by the randomized competitor (Rosso or Brunello). As price levels fluctuated above and below real median market prices and the experimental design is balanced (for all wines, each of

\footnotetext{
${ }^{8}$ Results for scenarios II and I are analogous, but we omit them for brevity. An earlier version of this article used information treatments and a set of descriptors capturing a participant's knowledge about wine were also included, similarly to Teisl and Roe (2010). Results are robust to either one of the approaches, but the use of cross-label perceptions results in a more predictive model for Eq. (10).
} 


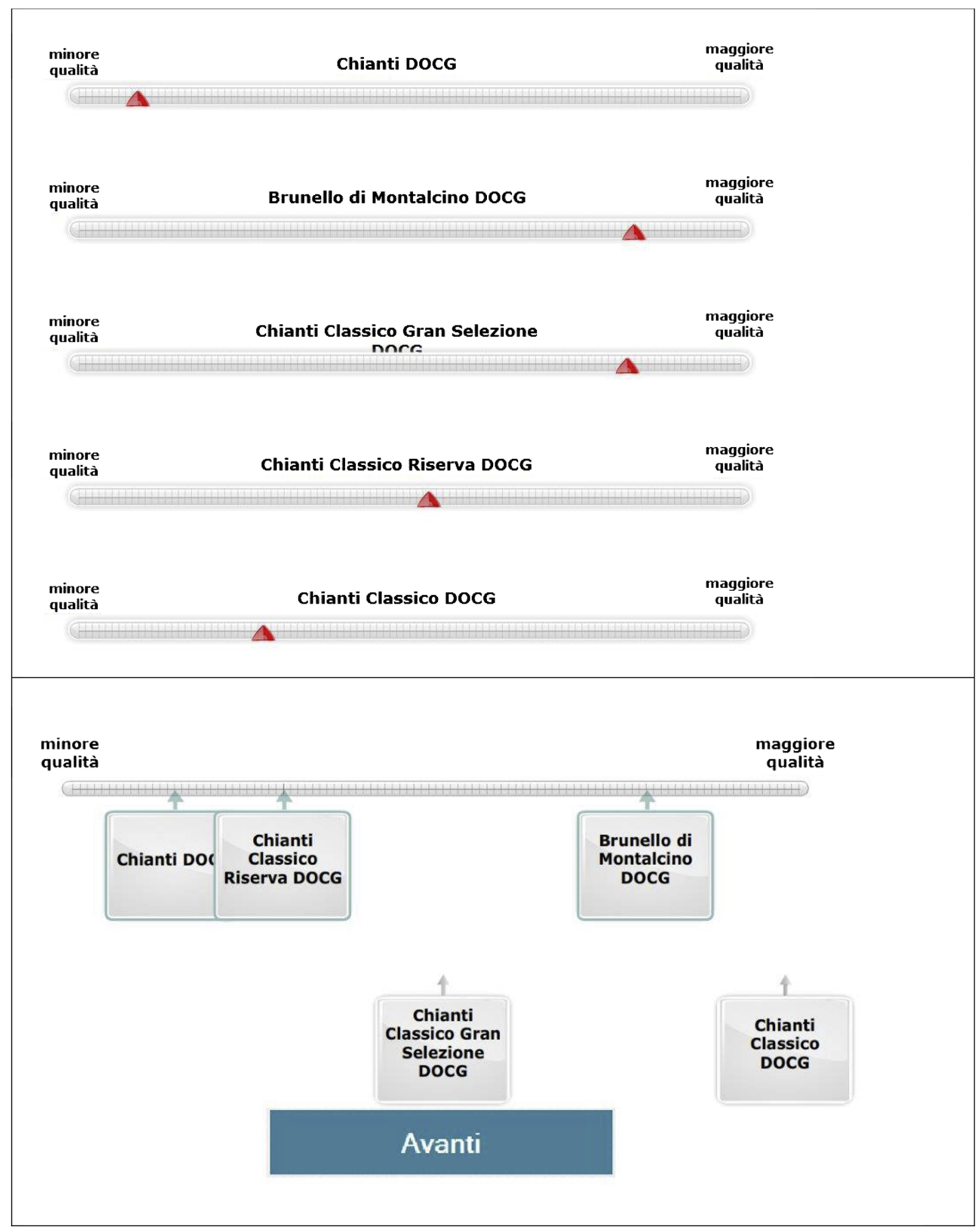

Fig. 2. Quality perception elicitation tools: Likert scale (Frame 1) and Drag-and-Drop Tool (Frame 2).

the four price levels occurs three times), the choice shares do have reasonable external validity. ${ }^{9}$ Several facts are noteworthy.

First, everyday consumption and special occasion choices have a

\footnotetext{
${ }^{9}$ An anonymous reviewer noted that, as the land in a GI is finite, the introduction of a new tier would change the supply schedule for the other wines over the longer term, possibly raising prices. This effect, if present, it is not captured here.
}

very different distribution of shares, as one would expect. When purchasing a wine for a meal at home, the preferred wines are the base Chianti and Rosso, with very few consumers willing to pay the high prices of a CCGS or Brunello. To the contrary, special occasion choices tend to gravitate towards the higher quality wines available (i.e. CCR, CCGS, Brunello), even though they are quite more expensive. It is also clear that Rosso can compete (i.e., gain significant shares) with Chianti wines in both every day and special occasion purchases, while Brunello 
Table 2

Mean quality perception (by Scenario) for Chianti (C), Chianti Classico (CC), Chianti Classico Riserva (CCR), Chianti Classico Gran Selezione (CCGS) by scenario, changes in perceptions (III-IV).

\begin{tabular}{|c|c|c|c|c|c|c|c|c|c|c|c|c|c|}
\hline & & & \multicolumn{2}{|l|}{$\mathrm{C}$} & \multicolumn{2}{|l|}{$\mathrm{CC}$} & \multicolumn{2}{|l|}{ CCR } & \multicolumn{2}{|l|}{ CCGS } & \multicolumn{2}{|l|}{ Rosso } & Brunello \\
\hline \multirow{2}{*}{ Scenario I } & \multicolumn{2}{|c|}{ Mean } & \multicolumn{2}{|c|}{71.49} & & & & & & & 69.69 & & 81.80 \\
\hline & \multicolumn{2}{|c|}{ S.E. Mean } & \multicolumn{2}{|c|}{1.65} & & & & & & & 2.74 & & 2.07 \\
\hline \multirow[t]{2}{*}{ Scenario II } & \multicolumn{2}{|c|}{ Mean } & \multicolumn{2}{|c|}{64.26} & \multicolumn{2}{|l|}{69.67} & & & & & 75.01 & & 81.32 \\
\hline & \multicolumn{2}{|c|}{ S.E. Mean } & \multicolumn{2}{|c|}{1.48} & \multicolumn{2}{|l|}{1.41} & & & & & 2.03 & & 1.84 \\
\hline \multirow[t]{2}{*}{ Scenario III } & \multicolumn{2}{|l|}{ Mean } & \multicolumn{2}{|c|}{59.24} & \multicolumn{2}{|l|}{65.45} & \multicolumn{3}{|l|}{78.63} & & \multicolumn{2}{|l|}{72.09} & 77.95 \\
\hline & \multicolumn{2}{|c|}{ S.E. Mean } & \multicolumn{2}{|c|}{1.32} & \multicolumn{2}{|l|}{1.13} & \multicolumn{2}{|l|}{1.08} & & & \multicolumn{2}{|l|}{1.98} & 1.89 \\
\hline \multirow[t]{2}{*}{ Scenario IV } & \multicolumn{2}{|c|}{ Mean } & 53.7 & & 58.79 & & 74.36 & & 77.16 & & 66.71 & & 78.49 \\
\hline & S.E. $\mathrm{Me}$ & & 1.13 & & 1.01 & & 0.92 & & 0.89 & & 1.64 & & 1.40 \\
\hline All Data & Mean & & 59.5 & & 63.28 & & 75.96 & & 77.16 & & 70.16 & & 79.36 \\
\hline & S.E. $\mathrm{Me}$ & & 0.71 & & 0.68 & & 0.71 & & 0.89 & & 1.01 & & 0.88 \\
\hline K Samples Median Test & chi2 & & 47.2 & & 28.09 & & 9.08 & & - & & 8.30 & & 1.32 \\
\hline & $\mathrm{p}$ & & 0.00 & & 0.000 & & 0.003 & & & & 0.040 & & 0.725 \\
\hline & & $\mathrm{C}$ & & CC & & CCR & & CCGS & & Rosso & & Brunell & \\
\hline & & Likert & Drag & Likert & Drag & Likert & Drag & Likert & Drag & Likert & Drag & Likert & Drag \\
\hline Constant (Avg. Qual. In Scen. III) & Coeff. & 66.28 & 53.09 & 70.51 & 61.02 & 81.34 & 76.27 & - & - & 78.00 & 68.14 & 82.44 & 72.83 \\
\hline & S.E & 1.83 & 1.99 & 1.70 & 1.71 & 1.50 & 1.67 & - & - & 2.85 & 2.85 & 2.32 & 2.86 \\
\hline & p. & 0.000 & 0.000 & 0.000 & 0.000 & 0.000 & 0.000 & - & - & 0.000 & 0.000 & 0.000 & 0.000 \\
\hline Scenario IV (Delta III vs. IV) & Coeff. & -5.85 & -6.20 & -6.53 & -7.57 & -2.25 & -6.79 & - & - & -6.68 & -5.00 & -1.47 & 2.25 \\
\hline & S.E & 2.28 & 2.56 & 2.11 & 2.20 & 1.86 & 2.15 & - & - & 3.54 & 3.64 & 2.89 & 3.70 \\
\hline & p. & 0.011 & 0.016 & 0.002 & 0.001 & 0.227 & 0.002 & - & - & 0.061 & 0.171 & 0.611 & 0.544 \\
\hline
\end{tabular}
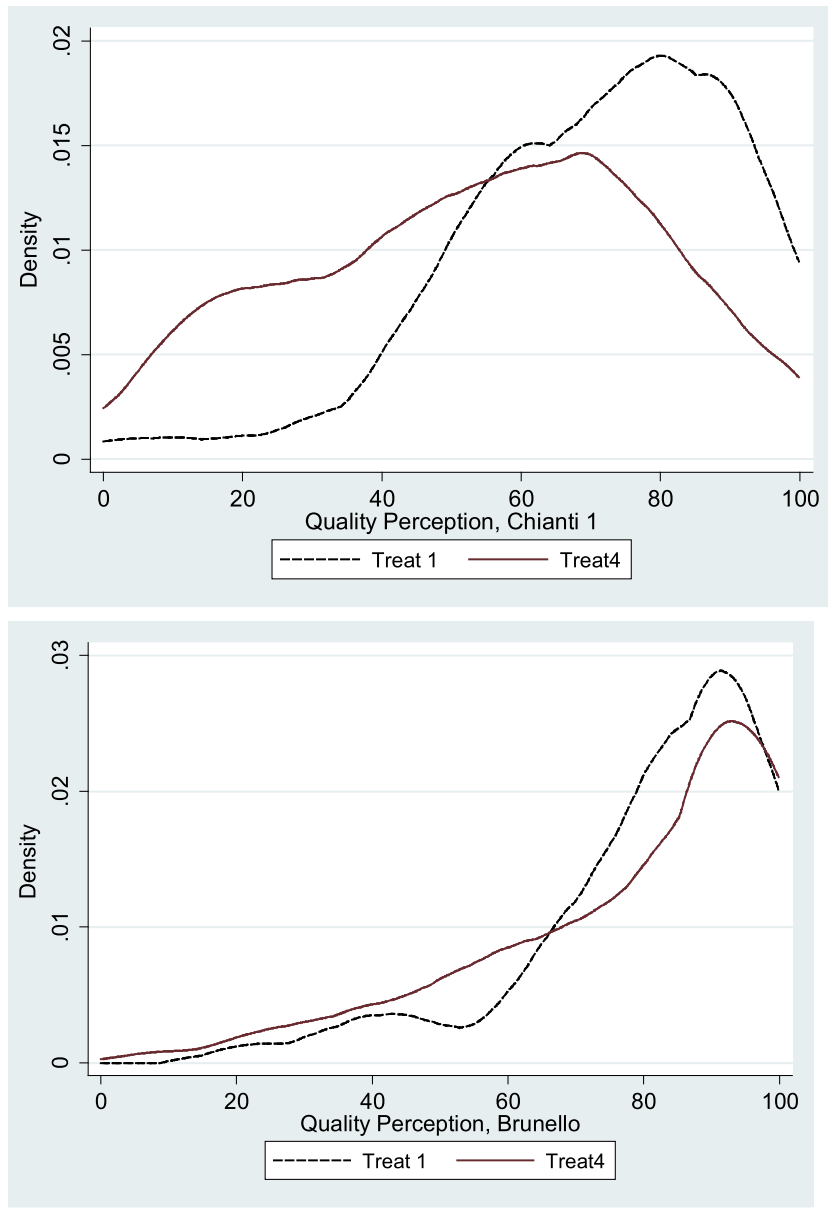

Fig. 3. Nonparametric density estimation of quality perceptions for Chianti (upper panel) and Brunello (lower panel). Comparison between Scenario I (dashed lines) and Scenario IV (solid line).

is often preferred for special occasions, but is probably considered too expensive for an everyday meal.

The second point worth noticing is that introducing higher tier
Chianti labels causes minimal changes in the shares of everyday consumption choices. Indeed, CC, CCR and CCGS obtain relatively small choice shares in all scenarios, especially when Rosso is available as competitor (however, value share are somewhat higher). The one discernible pattern is the reduction in opt-out choices as the number of available choices increases, but base Chianti and Rosso jointly maintain approximately $70 \%$ of the choice shares (across scenarios, irrespective of the presence of the higher quality wines.

Things are quite different for special occasion choices. In this case, for all labeling treatments the preferred Chianti wine is consistently the highest tier available, implying that consumers felt somewhat constrained in the treatments with fewer choices. Based on the results in Table 4, it is safe to assume that the vast majority of CCR, CCGS and Brunello sales relate to special occasion purchases. This is consistent with the findings of other wine marketing studies relating wine choices to the occasion of consumption (e.g. Hall et al., 2001; Quester and Smart, 1998; Boncinelli et al., 2019) which, while lower in volume, sustain the more profitable premium and ultra-premium markets (Bidmead, 2012).

Given the nature of our hypotheses and our interest for the effects of introducing the GS, we focus our modeling efforts and ensuing analysis on the special occasion choices, as they are more likely to be influenced by both the choice availability and perception restructuring effects (Eq. (6)) we aim to isolate. The empirical specification of the random WTP for quality model in Eq. (8), includes alternative-specific intercepts, the quality perceptions elicited in the experiment (QualExp), and the control function (Resid); which in scenario IV takes the form:

$$
\begin{aligned}
U_{i j}= & \beta_{0}(\mathrm{NONE})_{j}+\beta_{02} \mathrm{CC}_{j}+\beta_{03} \mathrm{CCR}_{j}+\beta_{04} \mathrm{CCGS}_{j}+\beta_{05} \text { Brunello }_{j} \\
& +\beta_{06} \text { Rosso }_{j}+\beta_{1} \text { Price }+\beta_{2}^{i} \text { QualExp }_{i j}+\beta_{3} \operatorname{Resid}_{i j}+\varepsilon_{i j} ;
\end{aligned}
$$

where $\beta_{2}^{i}$ is the single random parameter.

The first four column in Table 5 present the results from estimating Eq. (11) separately in each scenario. Price coefficients are negative in all treatments, with the exception of scenario IV, where it is non-significant. The estimate for the mean marginal utility of quality $E\left(\beta_{2}^{i}\right)$, the coefficient of the variable QualExp, is positive throughout the four samples, with significant and positive standard deviation (SD QualExp). The latter parameter provides a direct measure of dispersion of the valuation of quality in the consumer population, which we find to be heterogeneous. The parameter attached to the control function (Resid) is significant in scenarios III and IV (with larger sample size). 
Table 3

Instrumentation of quality perceptions via seemingly unrelated regression (scenarios III and IV).

\begin{tabular}{|c|c|c|c|c|c|c|c|c|c|c|}
\hline \multirow{2}{*}{$\begin{array}{l}\text { Dep. Var. } \\
\text { Competitor }\end{array}$} & \multicolumn{2}{|l|}{ C } & \multicolumn{2}{|l|}{$\mathrm{CC}$} & \multicolumn{2}{|l|}{ CCR } & \multicolumn{2}{|l|}{ CCGS } & \multirow[t]{2}{*}{ Brunello } & \multirow[t]{2}{*}{ Rosso } \\
\hline & Brunello & Rosso & Brunello & Rosso & Brunello & Rosso & Brunello & Rosso & & \\
\hline InfoLabel & -1.882 & -0.383 & -0.081 & 0.517 & -1.524 & -1.976 & 0.090 & 0.235 & -0.084 & 7.658 \\
\hline InfoNum & 0.145 & -0.389 & -0.006 & -0.073 & 0.488 & $1.994^{*}$ & 0.315 & $-1.770^{*}$ & -0.431 & 2.098 \\
\hline CompTable & 3.143 & -1.037 & -3.429 & 1.584 & $-5.279^{* * *}$ & $-7.587^{\text {**k }}$ & 3.095 & $7.999^{* * *}$ & $7.542^{\text {k*k }}$ & $-11.973^{\text {h.*x }}$ \\
\hline Frame1 & $-4.941^{k *}$ & -0.892 & 2.844 & 0.957 & 0.711 & -3.637 & -1.580 & 1.038 & -2.234 & $-7.148^{* * *}$ \\
\hline $\mathrm{C}$ & - & - & $0.711^{* * * * *}$ & $0.807^{* * * k}$ & $0.108^{\text {k*k }}$ & $0.375^{* * * k}$ & -0.050 & $-0.305^{* * * k}$ & $-0.372^{\text {k.k*k }}$ & -0.094 \\
\hline $\mathrm{CC}$ & $0.991^{k * * *}$ & $0.991^{\text {**** }}$ & - & - & $0.117^{*}$ & $-0.236^{\text {***kk}}$ & $0.106^{*}$ & $0.354^{\text {***ke }}$ & $0.408^{\text {***k }}$ & $0.289^{* k+k k}$ \\
\hline CCR & $0.157^{* * *}$ & $0.389^{* * * k}$ & $0.116^{*}$ & $-0.200^{\text {***k }}$ & - & - & $0.695^{\text {**** }}$ & $0.697^{\text {***ke }}$ & $0.247^{\text {ktkk }}$ & $-0.170^{*}$ \\
\hline CCGS & -0.063 & $-0.344^{\text {thetk }}$ & $0.101^{*}$ & $0.324^{* * * k}$ & $0.665^{k * k * k}$ & $0.751^{* * * k}$ & - & - & $0.247^{* * * *}$ & $0.207^{* * *}$ \\
\hline Brunello & $-0.297^{* * * k}$ & - & $0.232^{k k k k x}$ & - & $0.140^{\text {****** }}$ & - & $0.147^{\text {*k*k}}$ & - & - & - \\
\hline Rosso & - & -0.050 & - & $0.118^{\text {****k}}$ & - & $-0.083^{*}$ & - & $0.0950^{* * *}$ & - & - \\
\hline Cons & $13.999^{* * *}$ & -1.043 & $-14.383^{\text {*k*k }}$ & -3.862 & 0.908 & $14.022^{\text {*** }}$ & 7.307 & $18.227^{* k * k}$ & $37.328^{* * * *}$ & $46.454^{* * * *}$ \\
\hline $\mathrm{N}$ & 250 & 250 & 250 & 250 & 250 & 250 & 250 & 250 & 250 & 250 \\
\hline R-sq & 0.44 & 0.43 & 0.49 & 0.42 & 0.39 & 0.21 & 0.34 & 0.16 & 0.13 & 0.07 \\
\hline Chi2 & $509.8^{* * * * *}$ & $604.62^{* * * * *}$ & $576.99^{* * 2 \times k}$ & $585.05^{* * * * *}$ & $353.41^{* * * * *}$ & $265.37^{\text {*k:k*}}$ & $307.03^{\text {k.k*k}}$ & $250.5^{\text {*⿻一丿 }}$ & $98.91^{* * * * *}$ & $34.5^{* 2 \pi k t}$ \\
\hline InfoLabel & -2.264 & 2.783 & -0.186 & -1.120 & $7.281^{*}$ & 5.244 & - & - & 6.622 & 1.578 \\
\hline InfoNum & -0.417 & -2.937 & 1.706 & 0.402 & $-3.423^{\text {ktk }}$ & 2.159 & - & - & -1.287 & -0.894 \\
\hline CompTable & -3.689 & $10.139^{k * k}$ & -1.062 & -5.923 & 4.225 & -3.823 & - & - & 8.329 & 0.796 \\
\hline Frame1 & $-5.935^{* *}$ & -3.855 & 1.749 & -0.292 & $5.481^{\text {kik }}$ & 2.184 & - & - & $-9.450^{* * * *}$ & $-9.002^{* * k}$ \\
\hline C & - & - & $0.657^{* * * *}$ & $0.625^{* * * *}$ & 0.111 & $0.185^{\text {w*kik }}$ & - & - & $-0.208^{* * k}$ & -0.107 \\
\hline $\mathrm{CC}$ & $0.983^{k * * *}$ & $0.828^{* * * k}$ & - & - & $0.469^{\text {*k:k*k }}$ & $0.352^{* * * * k}$ & - & - & -0.062 & 0.031 \\
\hline CCR & 0.120 & $0.219^{* * k}$ & $0.321^{k * * * *}$ & $0.322^{k * * k}$ & - & - & - & - & $0.790^{* * * k}$ & $0.345^{* * * * k}$ \\
\hline CCGS & - & - & - & - & - & - & - & - & - & - \\
\hline Brunello & $-0.127^{* * *}$ & - & -0.018 & - & $0.420^{\text {k.k*k }}$ & - & - & - & - & - \\
\hline Rosso & - & -0.067 & - & 0.011 & - & $0.169^{\text {***k }}$ & - & - & - & \\
\hline Cons & 1.675 & -1.864 & -1.429 & 3.939 & 8.394 & $22.808^{k * k}$ & - & - & $32.988^{\text {kx/k }}$ & $55.789^{\text {***k}}$ \\
\hline $\mathrm{N}$ & 150 & 150 & 150 & 150 & 150 & 150 & - & - & 150 & 150 \\
\hline R-sq & 0.50 & 0.32 & 0.50 & 0.34 & 0.33 & 0.23 & - & & 0.17 & 0.05 \\
\hline Chi2 & $321.17^{\text {kn+kx}}$ & $191.3^{\text {kik:k}}$ & $355.86^{* * * * k}$ & $216.73^{\text {****}}$ & $163.74^{* * * * x}$ & $83.37^{* * x / k}$ & - & - & $88.69^{* k \times * k}$ & $16.46^{\text {k.k.k }}$ \\
\hline
\end{tabular}

$*, * * * * *$ indicate significance at alpha $=0.1,0.05$, and 0.01 respectively.

Table 4

Survey choice shares* and percent of value ${ }^{* *}$ (in parenthesis) for Every day consumption and special occasion.

\begin{tabular}{|c|c|c|c|c|c|c|c|c|c|c|c|c|c|}
\hline \multirow[b]{2}{*}{ Occasion } & \multirow[b]{2}{*}{ Sc. } & \multirow[b]{2}{*}{$\mathrm{N}^{*}$} & \multicolumn{8}{|c|}{ Chianti } & \multirow{2}{*}{\multicolumn{2}{|c|}{$\begin{array}{l}\text { Comp. } \\
\text { Rosso }\end{array}$}} & \multirow[b]{2}{*}{ None } \\
\hline & & & $\mathrm{C}$ & & $\mathrm{CC}$ & & CCR & & CCGS & & & & \\
\hline \multirow[t]{4}{*}{ Every Day } & 1 & 75 & 56.7 & $(67.5)$ & - & & - & & - & & 18.2 & $(32.5)$ & 25.1 \\
\hline & 2 & 125 & 54.3 & (55.6) & 4.8 & (10.6) & - & & - & & 22 & $(33.8)$ & 18.9 \\
\hline & 3 & 150 & 57.8 & (54.9) & 5.8 & (11.9) & 1.9 & $(6.0)$ & - & & 19.1 & $(27.2)$ & 15.3 \\
\hline & 4 & 250 & 50.6 & (44.4) & 5 & (9.5) & 2.2 & (6.4) & 2.4 & (8.8) & 23.4 & (30.8) & 16.3 \\
\hline \multirow[t]{4}{*}{ Special } & 1 & 75 & 29.1 & $(24.9$ & - & & - & & - & & 58.4 & $(75.1)$ & 12.4 \\
\hline & 2 & 125 & 9.5 & $(5.5)$ & 48.7 & (61.4) & - & & - & & 37.9 & $(33.1)$ & 3.9 \\
\hline & 3 & 150 & 5.7 & $(2.2)$ & 16.2 & (13.6) & 57.8 & $(74.8)$ & - & & 16.1 & $(9.4)$ & 4.1 \\
\hline & 4 & 250 & 5.4 & (1.8) & 10.3 & (7.3) & 25.4 & $(27.8)$ & 40.9 & $(56.0)$ & 14.4 & (7.1) & 3.5 \\
\hline Occasion & Sc. & $\mathrm{N}^{*}$ & $\mathrm{C}$ & & $\mathrm{CC}$ & & CCR & & CCGS & & Brunello & & None \\
\hline \multirow[t]{4}{*}{ Every Day } & 1 & 75 & 76.3 & (83.1) & - & & - & & - & & 3.1 & (16.9) & 20.6 \\
\hline & 2 & 125 & 67.2 & $(71.2)$ & 8.6 & (19.8) & - & & - & & 1.7 & $(9.0)$ & 22.5 \\
\hline & 3 & 150 & 69.9 & $(58.8)$ & 10.7 & (19.5) & 4.3 & (12.1) & - & & 2.3 & (9.7) & 12.8 \\
\hline & 4 & 250 & 70.3 & $(64.0)$ & 8.3 & (16.4) & 3 & $(9.1)$ & 1.2 & $(4.6)$ & 1.3 & (5.9) & 16 \\
\hline \multirow[t]{4}{*}{ Special } & 1 & 75 & 10.9 & $(2.6)$ & - & & - & & - & & 80.7 & (97.4) & 8.4 \\
\hline & 2 & 125 & 5.7 & (1.6) & 31.9 & (19.5) & - & & - & & 56.1 & (78.9) & 6.2 \\
\hline & 3 & 150 & 6.4 & (1.7) & 12.7 & $(7.2)$ & 25.1 & (21.8) & - & & 53.3 & (69.4) & 2.6 \\
\hline & 4 & 250 & 4.3 & (1.1) & 9.8 & (5.4) & 14.5 & (12.2) & 24.2 & (25.5) & 44.1 & (55.8) & 3.1 \\
\hline
\end{tabular}

* Each participant in $\mathrm{N}$ made 12 choices.

** Calculated with the median prices used in the experiments.

The alternative label-specific constants (CC, CCR, CCGS, Rosso, Brunello, $\mathrm{C}$ is the reference category) essentially measure label-specific factors affecting choice not controlled by our measurement of quality perceptions. Remaining differences could be ascribed to the different "prestige" of each wine, perhaps a relevant factor in special occasion purchases. ${ }^{10}$ One should be careful in drawing inferences from cross-

\footnotetext{
${ }^{10}$ Prestige can be conceptualized as one's perception of how other people or "experts" evaluate the wine, which does not necessarily coincide with an
}

sample differences in the parameters (the normalizing variance could be different), but the notable feature in Table 5 is how stable the estimates of $E\left(\beta_{2}^{i}\right)$ are across samples. This is fully consistent with the model presented in Eqs. (4) and (5), where the mean valuation of

(footnote continued)

individual's perceptions of quality. We considered eliciting the perceived prestige of a wine at the early stages of the design, but then decided to omit this construct from the final version of the survey because of collinearity and survey length concerns. 
Table 5

Estimated parameters for the random quality model (special occasion choices). scenario-specific and whole sample estimates. ${ }^{2}$

\begin{tabular}{|c|c|c|c|c|c|c|c|c|c|}
\hline \multirow[b]{2}{*}{ Variable } & \multicolumn{4}{|c|}{ Split Sample } & \multirow[b]{2}{*}{ Joint Slopes } & \multicolumn{4}{|c|}{ Scenario-Specific Intercepts } \\
\hline & Sc. I & Sc. II & Sc. III & Sc. IV & & I & II & III & IV \\
\hline \multirow[t]{3}{*}{$\mathrm{CC}$} & & 1.810 & 1.151 & 0.798 & & & 1.741 & 0.998 & 0.895 \\
\hline & & 0.097 & 0.098 & 0.080 & & & 0.082 & 0.090 & 0.078 \\
\hline & & 0.000 & 0.000 & 0.000 & & & 0.000 & 0.000 & 0.000 \\
\hline \multirow[t]{3}{*}{ CCR } & & & 1.996 & 1.150 & & & & 1.722 & 1.356 \\
\hline & & & 0.127 & 0.092 & & & & 0.096 & 0.086 \\
\hline & & & 0.000 & 0.000 & & & & 0.000 & 0.000 \\
\hline \multirow[t]{3}{*}{ CCGS } & & & & 1.529 & & & & & 1.802 \\
\hline & & & & 0.102 & & & & & 0.092 \\
\hline & & & & 0.000 & & & & & 0.000 \\
\hline \multirow[t]{3}{*}{ Rosso } & 0.942 & 1.144 & 0.348 & 0.566 & & 0.758 & 1.101 & 0.308 & 0.616 \\
\hline & 0.115 & 0.110 & 0.118 & 0.093 & & 0.104 & 0.107 & 0.113 & 0.093 \\
\hline & 0.000 & 0.000 & 0.003 & 0.000 & & 0.000 & 0.000 & 0.006 & 0.000 \\
\hline \multirow[t]{3}{*}{ Brunello } & 3.530 & 2.375 & 2.917 & 1.771 & & 2.109 & 2.156 & 2.433 & 2.104 \\
\hline & 0.409 & 0.213 & 0.173 & 0.121 & & 0.151 & 0.123 & 0.118 & 0.107 \\
\hline & 0.000 & 0.000 & 0.000 & 0.000 & & 0.000 & 0.000 & 0.000 & 0.000 \\
\hline \multirow[t]{3}{*}{ NoChoice } & -1.514 & -1.615 & -2.678 & -1.420 & & -1.329 & -1.333 & -2.365 & -1.631 \\
\hline & 0.695 & 0.258 & 0.287 & 0.174 & & 0.290 & 0.208 & 0.221 & 0.162 \\
\hline & 0.029 & 0.000 & 0.000 & 0.000 & & 0.000 & 0.000 & 0.000 & 0.000 \\
\hline \multirow[t]{3}{*}{ Price } & -0.067 & -0.016 & -0.029 & 0.003 & -0.010 & & & & \\
\hline & 0.014 & 0.008 & 0.006 & 0.003 & 0.003 & & & & \\
\hline & 0.000 & 0.031 & 0.000 & 0.366 & 0.000 & & & & \\
\hline \multirow[t]{3}{*}{ QualExp } & 0.043 & 0.045 & 0.050 & 0.043 & 0.045 & & & & \\
\hline & 0.012 & 0.006 & 0.007 & 0.004 & 0.003 & & & & \\
\hline & 0.000 & 0.000 & 0.000 & 0.000 & 0.000 & & & & \\
\hline \multirow[t]{3}{*}{ Resid } & -0.005 & 0.000 & -0.006 & -0.007 & -0.005 & & & & \\
\hline & 0.008 & 0.002 & 0.003 & 0.002 & 0.001 & & & & \\
\hline & 0.536 & 0.855 & 0.028 & 0.000 & 0.000 & & & & \\
\hline \multicolumn{10}{|l|}{ SD } \\
\hline \multirow[t]{3}{*}{ QualExp } & 0.067 & 0.075 & 0.097 & 0.076 & 0.079 & & & & \\
\hline & 0.008 & 0.006 & 0.008 & 0.004 & 0.003 & & & & \\
\hline & 0.000 & 0.000 & 0.000 & 0.000 & 0.000 & & & & \\
\hline 11 & -1095 & -2542 & -3688 & -7837 & $-15,188$ & & & & \\
\hline aic & 2204.1 & 5101.5 & 7394.6 & $15,694.5$ & $30,419.9$ & & & & \\
\hline bic & 2250.3 & 5160.6 & 7464.8 & $15,779.4$ & $30,621.8$ & & & & \\
\hline chi2 & 553.9 & 1024.5 & 1206.9 & 1814.7 & 4588.2 & & & & \\
\hline
\end{tabular}

a Each set of estimates include coefficient, standard error, and p-value.

quality $(\theta)$ does not change with the number of differentiating labels, but quality perceptions could (Eq. (6)).

We now can leverage this model to determine the extent to which the substitutions observed after introducing a higher-quality product can be traced to choice availability and/or restructuring of perceptions, as pointed in Eq. (6). Driven by our original motivation, we focus the simulation exercise on the transition from scenario III to IV, capturing the effect of the introduction of CCGS by the Chianti Classico Consortium. The identification strategy is to use the model to predict market shares in a market including CCGS, but hold quality perceptions for existing labels at the pre-CCGS levels, so that choice availability effects are isolated. To this end, we re-estimated the empirical model in Eq. (11) using the whole sample, with scenariospecific (I through IV) label intercepts, but joint slope estimates for the Price, Resid, and the random parameter $\beta_{2}^{i}$ for QualExp. Results are presented on the right-hand-side of Table 5 and show (statistically significant) negative price effects and positive, heterogeneous valuation of quality. Label-specific intercepts change across scenarios, but the consistent recognizable thread is that, holding quality perceptions and prices constant, Brunello is the most prestigious wine, followed by CCGS, CCR, CC, Rosso and the base Chianti.

Predicted shares of volume and value are presented in Table 6 for a simulated scenario including both Rosso and Brunello as competitor, ${ }^{11}$

\footnotetext{
${ }^{11}$ We also simulated market shares including only Rosso and only Brunello, but omit these results for brevity. Note that the Rosso + Brunello scenario may somewhat overestimate the total market share captured by the Montalcino wines, as substitution effects between Rosso and Brunello were not estimable given the experimental design. Results from the Brunello only scenario are most similar to what is presented in Table 6.
}

where we also report the source (i.e. scenario) of the estimated parameters and perceptions used in the simulation, the price, and the mean quality perceptions (see also Table 2). In terms of volume, the market share of Chianti goes from significantly trailing Montalcino wines in Scenario III (38\% Chianti vs. $52.4 \%$ Montalcino), to a position of market leadership (51.0\% Chianti vs. $38.3 \%$ Montalcino) in Scenario IV, making headway in the premium special occasion market segment. This jump is even more evident when considering market value, where the total Chianti share goes from $31 \%$ to $50.4 \%$. When made available, CCGS captures $23.5 \%$ of the special occasion choices ( $27.9 \%$ of value), even though only $51-38=13 \%$ of the market is gained from competitors or non-purchase decision, and the remaining $10.5 \%$ is cannibalized from other Chianti wines.

The third set of estimates in Table 6 show market shares re-estimated for Scenario IV, but holding quality perceptions constant at the scenario III estimates for all wines, except, obviously, CCGS. We find that, without restructuring of perceptions, the total Chianti share would sum up to $53.5 \%$ ( $54.1 \%$ of value), which implies that $53.5-51=2.5 \%$ (3.7\% in value) of the market is lost due to the restructuring of perception and comparative stigma. To put this in perspective, about a fourth $(2.5 / 10.5=24 \%)$ of the cannibalized choice share is owed to restructuring of perceptions and comparative stigma, while the remaining $80 \%$ is owed to the availability of a new choice.

\section{Conclusions, policy implications, limitations and future resarch}

Motivated by the case of the Chianti Classico wine consortium strategy, we study vertical differentiation via multi-tier quality certification labels tied to a Geographical Indication (GI). First, we model 
Table 6

Simulated choice shares and value shares (median prices) for special occasion purchases under different labeling regimes and scenarios.

\begin{tabular}{|c|c|c|c|c|c|c|c|c|}
\hline \multirow{2}{*}{$\begin{array}{l}\text { Treatment } \\
\text { Params. }\end{array}$} & \multirow[b]{2}{*}{ Qualexp } & \multirow[t]{2}{*}{ Wine } & \multirow{2}{*}{$\begin{array}{l}\text { Price } \\
€\end{array}$} & \multirow[t]{2}{*}{ QualExp } & \multicolumn{2}{|c|}{$\begin{array}{l}\text { Competitor } \\
\text { Choice Shares }\end{array}$} & \multicolumn{2}{|c|}{ Value Shares } \\
\hline & & & & & Share & Totals & & Totals \\
\hline 3 & 3 & $\mathrm{C}$ & 6 & 59.24 & $3.1 \%$ & $38.0 \%$ & $0.9 \%$ & $31.0 \%$ \\
\hline 3 & 3 & $\mathrm{CC}$ & 13 & 65.45 & $8.2 \%$ & & $5.0 \%$ & \\
\hline 3 & 3 & CCR & 20 & 78.63 & $26.7 \%$ & & $25.1 \%$ & \\
\hline 3 & 3 & Rosso & 9 & 72.09 & $5.1 \%$ & $52.4 \%$ & $2.2 \%$ & $69.0 \%$ \\
\hline 3 & 3 & Brunello & 30 & 77.95 & $47.3 \%$ & & $66.8 \%$ & \\
\hline 3 & 3 & None & 0 & 0 & $9.6 \%$ & $9.6 \%$ & & - \\
\hline 4 & 4 & $\mathrm{C}$ & 6 & 53.77 & $2.6 \%$ & $51.0 \%$ & $0.7 \%$ & $50.4 \%$ \\
\hline 4 & 4 & $\mathrm{CC}$ & 13 & 58.79 & $5.8 \%$ & & $3.6 \%$ & \\
\hline 4 & 4 & CCR & 20 & 74.36 & $19.1 \%$ & & $18.2 \%$ & \\
\hline 4 & 4 & CCGS & 25 & 77.16 & $23.5 \%$ & & $27.9 \%$ & \\
\hline 4 & 4 & Rosso & 9 & 66.71 & $5.1 \%$ & $38.3 \%$ & $2.2 \%$ & $49.6 \%$ \\
\hline 4 & 4 & Brunello & 30 & 78.49 & $33.2 \%$ & & $47.4 \%$ & \\
\hline 4 & 4 & None & 0 & 0 & $10.7 \%$ & $10.7 \%$ & & - \\
\hline 4 & 3 & $\mathrm{C}$ & 6 & 59.24 & $2.5 \%$ & $53.5 \%$ & $0.7 \%$ & $54.1 \%$ \\
\hline 4 & 3 & $\mathrm{CC}$ & 13 & 65.45 & $6.2 \%$ & & $4.0 \%$ & \\
\hline 4 & 3 & CCR & 20 & 78.63 & $23.1 \%$ & & $22.7 \%$ & \\
\hline 4 & 4 & CCGS & 25 & 77.16 & $21.7 \%$ & & $26.7 \%$ & \\
\hline 4 & 3 & Rosso & 9 & 72.09 & $5.9 \%$ & $35.3 \%$ & $2.6 \%$ & $45.9 \%$ \\
\hline 4 & 3 & Brunello & 30 & 77.95 & $29.4 \%$ & & $43.3 \%$ & \\
\hline 4 & 3 & None & 0 & 0 & $11.2 \%$ & $11.2 \%$ & - & - \\
\hline
\end{tabular}

how multi-tier labeling affects the quality output of a GI, and empirically test three competing hypotheses describing how consumer perceptions are altered by the introduction of a new quality tier. The fundamental point we raise is that consumers may interpret quality signals (including food labels) in a contextual rather than absolute manner; so that introducing new quality signals leads to a reassessment of the meaning and usefulness of other related cues.

Based on subjective ratings from an online experiment, the common assumption that consumers are well-informed and have rational quality expectations is rejected, but so is the polar opposite that consumers interpret new quality certification as independent from other labels from the same GI. The comparative stigma hypothesis on the other hand is not rejected, implying that introducing a new quality tier cheapens the perceived quality of pre-existing certifications marketed under the same GI umbrella. This results fits within the nascent agricultural economics literature investigating how food labels can change perception of unlabeled products (see, for example Kanter et al. (2009) or Costanigro and Lusk (2014)), providing additional impetus for expanding this line of research.

While the existing literature on GIs has treated quality signals as objective and uniformly understood by consumers, in this article we present a novel theoretical and empirical framework to study consumer choice in markets for vertically differentiated goods, where quality is credence or experience in nature. Our work extends previous models of demand for GI labels by introducing quality perceptions endogenous to the labeling regime, so that preferences for higher quality (i.e. choice availability) can be separated from the effects of perception restructuring.

The results of most immediate policy relevance are summarized in Fig. 4, where we graph the market share values (from Table 6) before the introduction of CCGS, after, and the effect of netting out the restructuring of quality perceptions caused by the new label. In the simulated environment of a choice experiment where Chianti wines compete with Montalcino wines, the introduction of the CCGS label increases the total share of Chianti wines from $31 \%$ of the market value to $50.4 \%$, while Montalcino falls from $69 \%$ to $49.6 \%$. This demonstrates how introducing a higher tier quality label, the Gran Selezione, is an effective tool to compete in the premium and ultra-premium market segments supported by special occasion purchases.
Additional evidence of the success of the Gran Selezione is provided by the label's adoption rates in the Chianti Classico area of production. According to the consortium ${ }^{12}$, the number of wineries producing Gran Selezione increased from 35 wineries in 2014 (out of 392 producers) to 95 in 2017. As we mentioned before, the general tenet in the industry is that the high-quality market segment allows wineries to charge substantive markups (Bidmead, 2012), and the limited information we have on production costs appears to confirm this. A study by Marone et al. (2017) assessed the median cost of production for a Brunello di Montalcino at $€ 9.28$, while the median (retail level) price we adopted here was $€ 30.00$. In sum, the multi-tier strategy of the Chianti Classico consortium increases the number of choices available to consumers while providing farmers' with new avenues to profitability, which is consistent with the intent of the EU GI directives (EU 1151/2012).

Even though the upwards expansion of the quality certification tiers appears to be a successful strategy from the perspective of the whole GI, this does not necessarily mean that all firms in a consortium will gain from it. Our findings show that the concern raised by Mr. Poggiali was a reasonable one, and indeed introducing the Gran Riserva cheapens how consumers perceive the quality of other Chianti wines. Based on our simulations, the most heavily impacted wine was the CC Riserva, suffering from significant cannibalization (from $25.1 \%$ to $18.2 \%$ of market value) attributable, at least in part, to the negative comparative stigma effects (holding perceived quality constant, the share would have been $22.7 \%$, rather than $18.2 \%$ ).

This highlights some important distributional tradeoffs. While the upward expansion strategy may make sense from a GI perspective, the Gran Selezione causes a transfer of revenue from wineries producing CCR as top quality to those producing CCGS. Sergio Zingarelli, president of the Consortium and an early promoter of the Gran Selezione labeling scheme, ${ }^{13}$ was quoted by the magazine Wine Enthusiast (O'Keefe, 2015) touting how "even some producers who initially spoke out against Gran Selezione are now making one, or planning on doing so". In many cases, the adoption of the new label may have been a forced choice, dictated by the need to avoid losing market to other firms

\footnotetext{
${ }^{12}$ Chianti Classico consortium, personal communication.

${ }^{13}$ For the curious reader, Rocca delle Macìe, the Estate owned by Sergio Zingarelli, does produce a Chianti Classico Gran Selezione.
} 


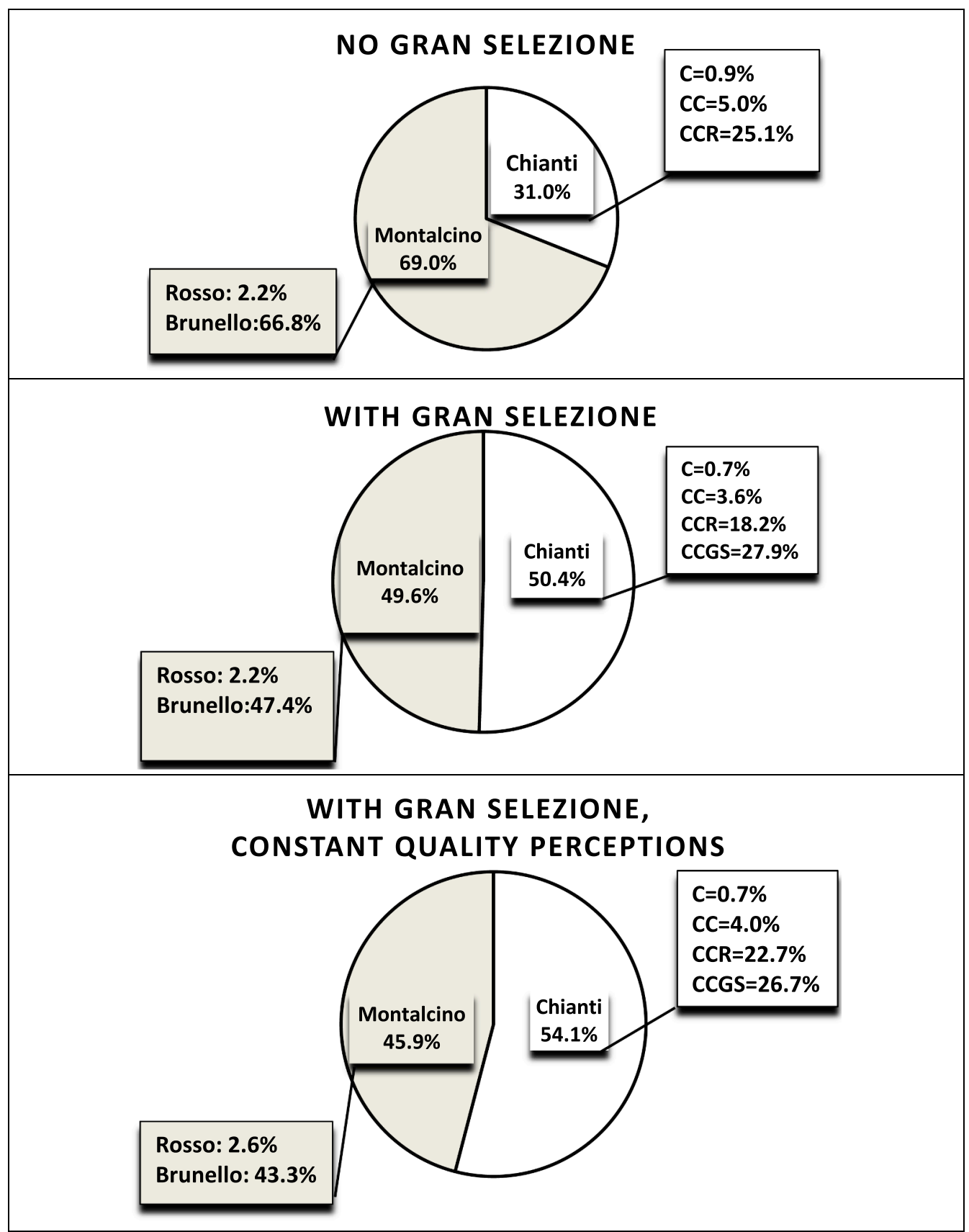

Fig. 4. Market shares (as \% of total \$ value of choices) before the introduction of CCGS (top panel), after its introduction (middle panel), and holding quality perceptions constant (lower panel).

within the consortium. More in general, GI consortia will want to ensure that no members face exogenous constraints in adopting the new label, or will likely face souring relationships.

In this article we take a substantive first step in studying multi-tier GI certification, but a number of limitation and caveats remain. For one, the sample we reached was representative of Italian wine consumers (inside and outside of Tuscany), but we did not consider the export and international markets, which can play an important role for high quality wines. The fundamental question is whether consumers abroad will recognize the new Gran Selezione as a signal of quality. The few studies considering the effect of GIs in international markets (e.g. see Menapace et al., 2011 on perceptions of Mediterranean olive oils in Canada) suggest that consumers may be more swayed by country of origin information, paying little attention to specific GI designations and distinctions. However, the success of Brunello di Montalcino and
Bordeaux wines in the export markets suggests that higher price, high involvement consumption choices may yield different outcomes.

From a methodological standpoint, concerns over tractability lead us to abstract from brand reputation dynamics, and yet it is possible that the perceived quality of a GI and comparative stigma effects may interact with the reputation of a specific winery. Pursuing this line of research would perhaps entail expanding on the brand/collective theory framework presented in Menapace and Moschini (2011) and the empirical approach adopted in Costanigro et al. (2010). Another relevant matter is determining how the optimal number of tiers in a given GI changes depending on the product and market conditions, as metaanalytical evidence shows that the effectiveness of GIs in inducing product differentiation varies (Deselnicu et al., 2013). This could be done via simulation (as in Costanigro et al., 2012), but a more detailed knowledge of production costs is necessary. 
The elephant in the room is the unresolved issue of appropriately representing and measuring how people form and use quality expectations, so a fundamental point in need of further scrutiny is the robustness of our results to the adoption of different elicitation tools. Unfortunately, this area of work received scant attention in the economics literature, where quality has been most often treated as an objective trait. For example, one could consider quality perceptions as a strictly qualitative concept, and elicit them indirectly via quality sorting tasks (e.g. this product is better tasting than another, see Costanigro et al. (2015)). Validated multi-question psychometric questionnaires (e.g. Jover et al., 2004) may yield measures with greater external validity, but complex, multidimensional constructs are hard to include in a concise model of vertical differentiation. The likert scales we adopted here relax the assumption of objectivity, but fit squarely with the representation of perceived quality as a spatial/cardinal concept. Recent work by Bordalo et al. (2013) on the role of saliency in the evaluation of price/quality tradeoffs suggests that the evaluation of quality may be much more context-dependent than our models are willing to concede. While this research area is currently unsettled, we are confident that introducing subjective perceptions within the economic framework of vertical differentiation can open the door to many important applications.

\section{Acknowledgments}

we are thankful to Alessndro Bonanno, Fabio Boncinelli and Caterina Contini for their useful feedback and comments. We also acknowledge the contribution of three anonymous referees who gave insightful critique of an early version of the article.

\section{References}

Akerlof, George A., 1970. The market for 'lemons': quality uncertainty and the market mechanism. Q. J. Econ. 84 (3), 488-500.

Almenberg, Johan, Dreber, Anna, 2011. When does the price affect the taste? Results from a wine experiment. J. Wine Econ. 6 (01), 111-121. https://doi.org/10.1017/ S1931436100001085.

Andersen, Steffen, Harrison, Glenn W., Lau, Morten Igel, Elisabet Rutström, E., 2006. Elicitation using multiple price list formats. Experim. Econ. 9 (4), 383-405. https:// doi.org/10.1007/s10683-006-7055-6.

Bekker-Grob, Esther W. de., Hol, Lieke, Donkers, Bas, Leonie van Dam, J., Habbema, Dik F., van Leerdam, Monique E., Kuipers, Ernst J., Essink-Bot, Marie-Louise, Steyerberg, Ewout W., 2010. Labeled versus unlabeled discrete choice experiments in health economics: an application to colorectal cancer screening. Val. Health 13 (2), 315-323. https://doi.org/10.1111/j.1524-4733.2009.00670.x.

Bidmead, Warren, 2012. Wine pricing in the United States. The Oxford Handbook of Pricing Management, June. https://doi.org/10.1093/oxfordhb/9780199543175. 013.0015 .

Bockstael, Nancy E., 1984. The welfare implications of minimum quality standards. Am. J. Agric. Econ. 66 (4), 466-471. https://doi.org/10.2307/1240925.

Boncinelli, Fabio, Dominici, Andrea, Gerini, Francesca, Marone, Enrico, 2019. Consumers wine preferences according to purchase occasion: personal consumption and giftgiving. Food Qual. Prefer. 71 (January), 270-278. https://doi.org/10.1016/j. foodqual.2018.07.013.

Bonroy, Olivier, Constantatos, Christos, 2014. On the economics of labels: how their introduction affects the functioning of markets and the welfare of all participants. Am. J. Agric. Econ. (September), aau088. https://doi.org/10.1093/ajae/aau088.

Boom, Anette, 1995. Asymmetric international minimum quality standards and vertical differentiation. J. Ind. Econ. 43 (1), 101-119. https://doi.org/10.2307/2950427.

Bordalo, Pedro, Gennaioli, Nicola, Shleifer, Andrei, 2013. Salience and consumer choice. J. Pol. Econ. 121 (5), 803-843. https://doi.org/10.1086/673885.

Brook, Stephen, 2014. Chianti Classico Gran Selezione: Top Tier or Just Another Layer? Decanter 2014. http://www.decanter.com/features/chianti-classico-gran-selezionetop-tier-or-just-another-layer-245910/.

Brooks, Kathleen, Lusk, Jayson L., 2010. Stated and revealed preferences for organic and cloned milk: combining choice experiment and scanner data. Am. J. Agric. Econ. 92 (4), 1229-1241. https://doi.org/10.1093/ajae/aaq054.

Caldieraro, Fabio, Kao, Ling-Jing, Cunha Jr., Marcus, 2015. Harmful upward line extensions: can the launch of premium products result in competitive disadvantages? J. Market. 79 (6), 50-70. https://doi.org/10.1509/jm.14.0100.

Chintagunta, Pradeep K., 1996. Investigating the effects of a line extension or new brand introduction on market structure. Market. Lett. 7 (4), 319-328.

Costanigro, Marco, Appleby, Christopher, Menke, Stephen D., 2014a. The wine headache: consumer perceptions of sulfites and willingness to pay for non-sulfited wines. Food Qual. Prefer. 31 (January), 81-89. https://doi.org/10.1016/j.foodqual.2013.08.002.

Costanigro, Marco, Bond, Craig A., McCluskey, Jill J., 2012. Reputation leaders, quality laggards: incentive structure in markets with both private and collective reputations. J. Agric. Econ. 63 (2), 245-264. https://doi.org/10.1111/j.1477-9552.2011.00331.x. Costanigro, Marco, Deselnicu, Oana, Kroll, Stephan, 2015. Food beliefs: elicitation, estimation and implications for labeling policy. J. Agric. Econ. 66 (1), 108-128. https:// doi.org/10.1111/1477-9552.12085.

Costanigro, Marco, Kroll, Stephan, Thilmany, Dawn, Bunning, Marisa, 2014b. Is it love for local/organic or hate for conventional? Asymmetric effects of information and taste on label preferences in an experimental auction. Food Qual. Prefer. 31 (January), 94-105. https://doi.org/10.1016/j.foodqual.2013.08.008.

Costanigro, Marco, Lusk, Jayson L., 2014. The signaling effect of mandatory labels on genetically engineered food. Food Pol. 49 (Part 1), 259-267. https://doi.org/10. 1016/j.foodpol.2014.08.005. December.

Costanigro, Marco, McCluskey, Jill J., Goemans, Christopher, 2010. The economics of nested names: name specificity, reputations, and price premia. Am. J. Agric. Econ. 92 (5), 1339-1350. https://doi.org/10.1093/ajae/aaq065.

Costanigro, Marco, McCluskey, Jill J., Mittelhammer, Ron C., 2007. Segmenting the wine market based on price: hedonic regression when different prices mean different products. J. Agric. Econ. 58 (3), 454-466. https://doi.org/10.1111/j.1477-9552. 2007.00118.x.

Darby, Michael R., Karni, Edi, 1973. Free competition and the optimal amount of fraud. J. Law Econ. 16 (1), 67-88.

Deselnicu, Oana C., Costanigro, Marco, Souza-Monteiro, Diogo M., McFadden, Dawn Thilmany, 2013. A meta-analysis of geographical indication food valuation studies: what drives the premium for origin-based labels? J. Agric. Resour. Econ. 38 (2), 204-219.

Desquilbet, Marion, Monier-Dilhan, Sylvette, 2015. Are geographical indications a worthy quality label? A framework with endogenous quality choice. Eur. Rev. Agric. Econ. 42 (1), 129-150. https://doi.org/10.1093/erae/jbu008.

Gergaud, Olivier, Livat, Florine, Rickard, Bradley, Warzynski, Frederic, 2017. Evaluating the net benefits of collective reputation: the case of bordeaux wine. Food Pol. 71 (August), 8-16. https://doi.org/10.1016/j.foodpol.2017.07.002.

Gragnani, Matteo, 2013. The EU regulation 1151/2012 on quality schemes for agricultural products and foodstuffs. Eur. Food Feed Law Rev. 8 (6), 376-385.

Gustafson, Christopher R., Lybbert, Travis J., Sumner, Daniel A., 2016. Consumer knowledge affects valuation of product attributes: experimental results for wine. J. Behav. Experim. Econ. 65 (Suppl. C), 85-94. https://doi.org/10.1016/j.socec.2016. 08.004 .

Hall, John, Lockshin, Larry, O’ Mahony, G. Barry, 2001. Exploring the links between wine choice and dining occasions: factors of influence. Int. J. Wine Market. 13 (1), 36-53. https://doi.org/10.1108/eb043369.

Heath, Timothy B, DelVecchio, Devon, McCarthy, Michael S, 2011. The asymmetric effects of extending brands to lower and higher quality. J. Market. 75 (4), 3-20. https://doi.org/10.1509/jmkg.75.4.3.

Kadiyali, Vrinda, Vilcassim, Naufel, Chintagunta, Pradeep, 1998. Product line extensions and competitive market interactions: an empirical analysis. J. Econ. 89 (1-2), 339-363. https://doi.org/10.1016/S0304-4076(98)00066-9.

Kahneman, Daniel, Knetsch, Jack L., Thaler, Richard H., 1991. Anomalies: the endowment effect, loss aversion, and status quo bias. J. Econ. Perspect. 5 (1), 193-206.

Kanter, Christopher, Messer, Kent D., Kaiser, Harry M., 2009. Does production labeling stigmatize conventional milk? Am. J. Agric. Econ. 91 (4), 1097-1109. https://doi. org/10.1111/j.1467-8276.2009.01317.x.

Lee, Wan-chen Jenny, Shimizu, Mitsuru, Kniffin, Kevin M., Wansink, Brian, 2013. You taste what you see: do organic labels bias taste perceptions? Food Qual. Prefer. 29 (1), 33-39. https://doi.org/10.1016/j.foodqual.2013.01.010.

Leland, Hayne E., 1979. Quacks, lemons, and licensing: a theory of minimum quality standards. J. Pol. Econ. 87 (6), 1328-1346.

Lusk, Jayson L., Schroeder, Ted C., Tonsor, Glynn T., 2013. Distinguishing beliefs from preferences in food choice. Eur. Rev. Agric. Econ. (December), jbt035. https://doi. org/10.1093/erae/jbt035.

Malone, Trey, Lusk, Jayson L., 2017a. An instrumental variable approach to distinguishing perceptions from preferences for beer brands. Manage. Decis. Econ. 39 (4), 403-417. https://doi.org/10.1002/mde.2913.

Malone, Trey, Lusk, Jayson L., 2017b. Taste trumps health and safety: incorporating consumer perceptions into a discrete choice experiment for meat. J. Agric. Appl. Econ. 49 (1), 139-157. https://doi.org/10.1017/aae.2016.33.

Manski, Charles F., 2004. Measuring expectations. Econometrica 72 (5), 1329-1376. https://doi.org/10.1111/j.1468-0262.2004.00537.x.

Marone, Enrico, Bertocci, Marco, Boncinelli, Fabio, Marinelli, Nicola, 2017. The cost of making wine: a tuscan case study based on a full cost approach. Wine Econ. Pol. 6 (2), 88-97. https://doi.org/10.1016/j.wep.2017.06.002.

McFadden, Brandon R., Lusk, Jayson L., 2015. Cognitive biases in the assimilation of scientific information on global warming and genetically modified food. Food Pol. 54 (July), 35-43. https://doi.org/10.1016/j.foodpol.2015.04.010.

McFadden, Daniel, Train, Kenneth, 2000. Mixed MNL models for discrete response. J. Appl. Econ. 15 (5), 447-470.

Meloni, Giulia, Swinnen, Johan, 2018. Trade and Terroir. The Political Economy of the World's First Geographical Indications. Food Policy 81 (December), 1-20. https:// doi.org/10.1016/j.foodpol.2018.10.003.

Menapace, Luisa, Colson, Gregory, Grebitus, Carola, Facendola, Maria, 2011. Consumers' preferences for geographical origin labels: evidence from the Canadian olive oil market. Eur. Rev. Agric. Econ.(January). https://doi.org/10.1093/erae/jbq051.

Menapace, Luisa, Moschini, GianCarlo, 2011. Quality certification by geographical indications, trademarks and firm reputation. Eur. Rev. Agric. Econ.(November). https://doi.org/10.1093/erae/jbr053.

Mérel, Pierre, Sexton, Richard J., 2012. Will geographical indications supply excessive quality? Eur. Rev. Agric. Econ. 39 (4), 567-587. https://doi.org/10.1093/erae/ 
jbr056.

Messer, Kent D., Costanigro, Marco, Kaiser, Harry M., 2017. Labeling food processes: the good, the bad and the ugly. Appl. Econ. Perspect. Pol. 39 (3), 407-427. https://doi. org/10.1093/aepp/ppx028.

Moschini, GianCarlo, Menapace, Luisa, Pick, Daniel, 2008. Geographical indications and the competitive provision of quality in agricultural markets. Am. J. Agric. Econ. 90 (3), 794-812. https://doi.org/10.1111/j.1467-8276.2008.01142.x.

Mueller, Simone, Patricia Osidacz, I., Francis, Leigh, Lockshin, Larry, 2010. Combining discrete choice and informed sensory testing in a two-stage process: can it predict wine market share? Food Qual. Prefer. 21 (7), 741-754. https://doi.org/10.1016/j. foodqual.2010.06.008.

Mussa, Michael, Rosen, Sherwin, 1978. Monopoly and product quality. J. Econ. Theory 18 (2), 301-317.

Nelson, Phillip, 1970. Information and consumer behavior. J. Pol. Econ. 78 (2), 311-329.

O'Keefe, Kerin, 2015. Chianti Classico Gran Selezione: Quality Quells Critics. Wine Enthusiast Magazine. https://www.winemag.com/2015/06/18/chianti-classicogran-selezione-quality-quells-critics/.

Quester, Pascale G., Smart, Justin, 1998. The influence of consumption situation and product involvement over consumers' use of product attribute. J. Consum. Market. 15 (3), 220-238. https://doi.org/10.1108/07363769810219107.

Petrin, Amil, Train, Kenneth, 2010. A control function approach to endogeneity in consumer choice models. J. Mark. Res. 47 (1), 3-13. https://doi.org/10.1509/jmkr.47. 1.3.

Plassmann, Hilke, O’Doherty, John, Shiv, Baba, Rangel, Antonio, 2008. Marketing actions can modulate neural representations of experienced pleasantness. PNAS 105 (3), 1050-1054. https://doi.org/10.1073/pnas.0706929105.
Randall, Taylor, Ulrich, Karl, Reibstein, David, 1998. Brand equity and vertical product line extent. Market. Sci. 17 (4), 356-379. https://doi.org/10.1287/mksc.17.4.356.

Shapiro, Carl, 1983. Premiums for high quality products as returns to reputations. Q. J. Econ. 98 (4), 659-680.

Steenkamp, Jan-Benedict E.M., 1990. Conceptual model of the quality perception process J. Bus. Res. 21 (4), 309-333. https://doi.org/10.1016/0148-2963(90)90019-A.

Teisl, Mario F., Roe, Brian E., 2010. Consumer willingness-to-pay to reduce the probability of retail foodborne pathogen contamination. Food Pol. 35 (6), 521-530. https://doi.org/10.1016/j.foodpol.2010.07.003.

Teuber, Ramona, 2011. Consumers' and producers' expectations towards geographical indications: empirical evidence for a german case study. British Food J. 113 (7), 900-918. https://doi.org/10.1108/00070701111148423.

Torrisi, Francesco, Stefani, Gianluca, Seghieri, Chiara, 2006. Use of scanner data to analyze the table wine demand in the italian major retailing trade. Agribusiness 22 (3), 391-403. https://doi.org/10.1002/agr.20093.

Jover, Verdú, Antonio, J., Montes, Francisco Javier Lloréns, Fuentes, María del Mar Fuentes, 2004. Measuring perceptions of quality in food products: the case of red wine. Food Qual. Prefer. 15 (5), 453-469. https://doi.org/10.1016/j.foodqual.2003. 08.002 .

Winfree, Jason A., McCluskey, Jill J., 2005. Collective reputation and quality. Am. J. Agric. Econ. 87 (1), 206-213. https://doi.org/10.1111/j.0002-9092.2005.00712.x. Zago, Angelo M., Pick, Daniel, 2004. Labeling policies in food markets: private incentives, public intervention, and welfare effects. J. Agric. Resour. Econ. 29 (01).

Zellner, Arnold, 1962. An efficient method of estimating seemingly unrelated regressions and tests for aggregation bias. J. Am. Stat. Assoc. 57 (298), 348-368. https://doi.org/ $10.2307 / 2281644$ 